\title{
Heating Preciosity-Trends in Modern Oncological Hyperthermia
}

\author{
Oliver Szasz' ${ }^{1}$ Marcell A. Szasz ${ }^{2}$, Carrie Minnaar ${ }^{3}$, Andras Szasz ${ }^{1,4^{*}}$ \\ ${ }^{1}$ Biotechnics Department, Faculty of Engineering, St. István University, Godollo, Hungary \\ ${ }^{2}$ Cancer Center, Semmelweis University, Budapest, Hungary \\ ${ }^{3}$ Department of Radiation Sciences, University of the Witwatersrand, Johannesburg, South Africa \\ ${ }^{4}$ Faculty of Information Technology and Bionics, Pazmany P. Catholic University, Budapest, Hungary \\ Email: ^biotech@gek.szie.hu
}

How to cite this paper: Szasz, O., Szasz, M.A., Minnaar, C. and Szasz, A. (2017) Heating Preciosity-Trends in Modern Oncological Hyperthermia. Open Journal of Biophysics, 7, 116-144.

https://doi.org/10.4236/ojbiphy.2017.73010

Received: June 1, 2017

Accepted: July 3, 2017

Published: July 6, 2017

Copyright (c) 2017 by authors and Scientific Research Publishing Inc. This work is licensed under the Creative Commons Attribution International License (CC BY 4.0).

http://creativecommons.org/licenses/by/4.0/ c) (i) Open Access

\begin{abstract}
The use of hyperthermia as a treatment in oncology is a common topic for debate. Some researchers expect a breakthrough in oncological treatments with hyperthermia, whereas others have disregarded the method. Serious questions concerning hyperthermia have arisen. Should homogeneous (isothermal) or heterogeneous (selective) heating being used? When we use selective heating (heterogeneity), should the entire tumour be targeted or should the malignant cells be individually selected? Does the mechanism involve thermal cell death or thermally-assisted cell death? Is the goal necrosis or apoptosis? Is hyperthermia safe as a monotherapy or does it have to be combined with conventional treatments? When the selection is local, how do we act on disseminated cells that represent a high risk of life threatening metastases? When local heating is the focus, how should it be carried out with measured and controlled? Our objective is to show how precise, selective heat transfer is necessary to remove malignant cells and, consequently, how hyperthermia as part of the immune-oncology can change the game in this promising field of oncological therapies.
\end{abstract}

\section{Keywords}

Heating Preciosity, Hyperthermia, Oncology, Immune Effects, Bystander-Effect, Abscopal Effect

\section{Introduction}

Hyperthermia in oncology has a long and controversial history. The technical challenges together with our incomplete understanding of the bio-electromagnetic mechanisms have made it difficult to accept hyperthermia as a standard treat- 
ment for oncological applications.

A large number of publications have addressed numerous questions [1] [2] [3], and the results were promising: hyperthermia increases the efficacy of radiotherapy (RT) by a factor of $1.2-5$, and chemotherapy (CT) by a factor $1.2-10$, [4]. In some studies, hyperthermia shows much better results than any other oncotherapy [7].

However, doubts about hyperthermia still remain despite the successful applications [5]. The critics of hyperthermia highlight the special conditions that are necessary for the above results and questioning the applicability of hyperthermia [6].

Due to the incomplete understanding of the underlying mechanisms of hyperthermia in oncotherapy, the controversies block the expansion of clinical applications [6].

Recently, a robust change in the paradigm of modern medicine has occurred. The conventional treatments that are usually applied in addition to hyperthermia have developed rapidly. The new therapies now compete with hyperthermia rather than work alongside it. Gold standard treatments, such as chemotherapy, have become more targeted, utilizing more sophisticated antibody, nano-delivery [7], and liposomal [8] [9] delivery methods. These treatments are personalized and the local control of the tumour is secondary to survival and quality of life. Other treatment modalities, including radiotherapy, have changed drastically as well. Radiotherapy uses more precise tomotherapy [10], deep-controlled proton therapy [11], and has intensified with interventional nano-radiation [12]. Even hyperthermia itself has shifted to ablative techniques, laser-induced techniques [13] (including PDT [14]), and nanoparticle heating [15], with the definite aim of immune modulation. The paradigm in oncology is quickly changing toward immune-oncology and integrative personalized therapies.

The paradigm of hyperthermia is simple: heat with as high power as power, and see what happens. Dr. Storm provided one critique, stating that "the mistakes made by the hyperthermia community may serve as lessons, not to be repeated by investigators in other novel fields of cancer treatment" [16]. We have to face the challenges and the limits of hyperthermia applications anticipating the advice of Albert Einstein: "once we accept our limits, we go beyond them" [17].

\subsection{Hyperthermia Used as a Monotherapy or a Complementary Therapy?}

Hyperthermia in oncology is certainly a complementary therapy, as part of a complex treatment. It is frequently used alongside radio or chemotherapy, but pre- or post-surgical applications are also feasible.

However, most of the experimental research on hyperthermia has focused on in vitro or in vivo models. In these models, no active physiological control exists. Furthermore, most of the experimental research models use hyperthermia as a monotherapy, whereas it is used almost solely as a complementary therapy in 


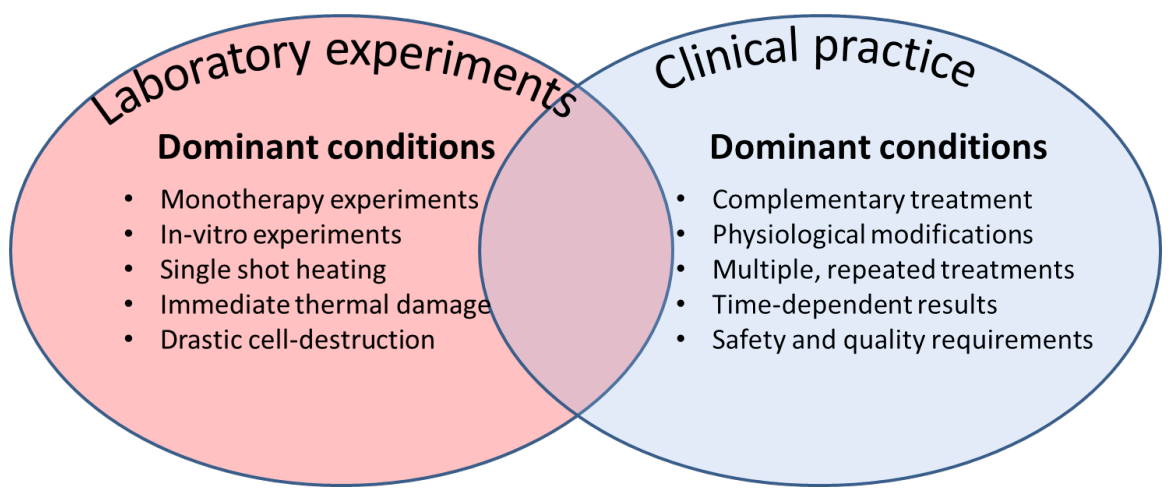

Figure 1. The laboratory research is usually far from the clinical practice.

clinical practice. The research basis of the other therapies is much more supportive of the clinical applications. This includes the fact that the research does not model the real treatment close enough, Figure 1.

The effects of various in-vitro heating experiments differ from the clinically applied complementary thermo-therapies. The synergism of their impacts needs complex cross-interactions between the heat and its complementary counterpart. Sole hyperthermia experiments in vitro can show the cellular and molecular changes, but these are independent from the complementary treatments in vivo and in clinical practice. The sole heating applications give simple additional effects, do not regarded as realistic synergetic models, though these could give useful information about the immunological consequences of the cell death when these processes are free from the clinically applied complementary additions.

\subsection{Systemic or loco-Regional Heating?}

Homogeneous heating, known as whole-body hyperthermia (WBH), involves heating the whole body (up to $42^{\circ} \mathrm{C}$ [18] or over [19]) to target all of the malignant cells in the body. However, the high systemic temperature did not work as expected, approximately doubling the probability of metastases compared to local temperature treatment [20]. A comparison between local and systemic heating showed that WBH had less local control when combined with chemotherapy, a shorter time to progression, and a shorter survival time than local heating [21]. Furthermore, neutropenia and thrombocytopenia were also more severe in WBH than with the local heating method [21]. The potential toxicity, together with shorter survival, was also confirmed in another trial [22].

There is further evidence of these problems from an earlier veterinary clinical trial. Without evidence of metastases, local radiation with complementary WBH was performed [23] [24] as a treatment for canine osteosarcoma. This combination of treatment was ineffective on the primary tumour, but rapid and massive metastases developed in distant organs including the lung. Furthermore, the chemo-drugs Bleomycin and Cisplatin have been found to turn carcinogenic in vitro by heat-therapy [25] [26] [27].

Therefore, contrary to the expectations that the homogeneous high tempera- 
ture $\left(42^{\circ} \mathrm{C}\right)$ will offer better results, we found a less therapeutic outcome than with local, non-homogeneous heating. Like Thomas Huxley said, "The great tragedy of science-the slaying of a beautiful hypothesis by an ugly fact." [28].

However, a more moderate WBH method has been suggested, where mild hyperthermia is induced. Moderate WBH is very promising for immune stimulation and for sensitizing the conventional gold-standard therapies like chemotherapy or radiotherapy.

The focus of WBH using higher temperatures gradually shifted toward loco-regional heating. The most important consideration is the physiological feedback reaction to the heating process. The thermal homeostasis actively works against the heating processes, fighting not only against the disease but against our action as well. The appeared contra-effects are clear demands to shift from the direct aggressive cell-distortion to support the natural physiological feedback mechanisms eliminate the malignant cells and processes, [29], Figure 2 .

\subsection{How Local Is the Local Treatment?}

Loco-regional hyperthermia is homogenous because it neglects the disseminated cells and does not take care of far distant metastases; however, its results are promising for local control and the remission rate using this method is positive.

Contrary to long traditions, a new approach was gradually developed that involves heating with nanoparticles. This new technology uses nanoparticles as vehicles with various effects on the malignant cells, and can be used to transfer heat energy. The nanoparticles select the malignant cells by appropriate antibody

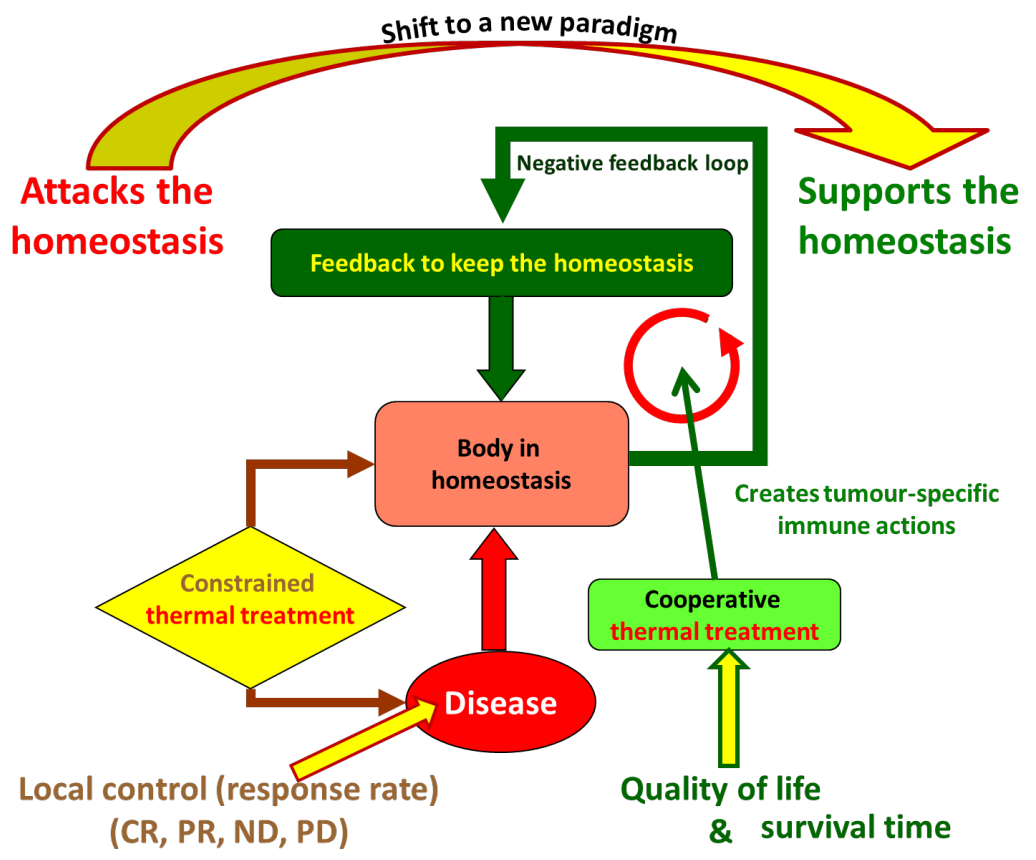

Figure 2. Support of the complex homeostatic feedback mechanisms could be more effective than the constrained thermal action on the local tumour. The results of this paradigm should be measured by survival time and quality of life. 


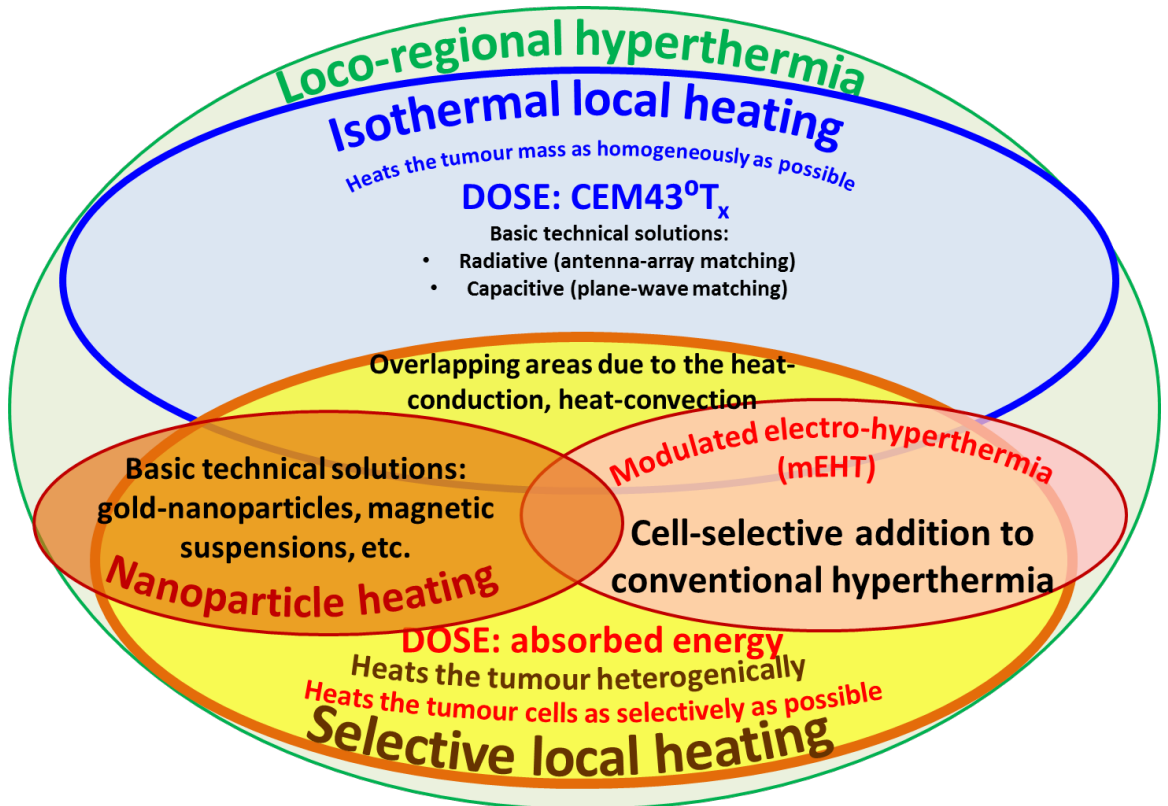

Figure 3. Two main groups of loco-regional hyperthermia: the isothermal homogeneous heating and the heterogenic selective heating.

conjugation, and the absorbed heat can be concentrated in the nanoparticles so that the cancer cells are directly targeted. For example, ferromagnetic nanoparticles alone could be heated by a magnetic field, since the magnetic field absorption in tissues is negligible, and then that heat can be transferred into the tumour.

This new technology represents an independent category of hyperthermia. The local, cellular selection method overlaps with the conventional isothermal one due to the heat flow from these particles into their neighbourhood. Another independent and selective local heating method, called modulated electro-hyperthermia (mEHT, trade name: oncothermia), is very similar to the nanoparticle methods, Figure 3. The only difference is the use of natural, readily available nanoparticles in the malignant cells, which can be chosen by their biophysical properties [30].

Challenges in local heat therapies. Spontaneous distant metastases were observed in canines with local heat therapies [31], and possible induced tumour progression was seen in other animal models [32]. The central task was to investigate the correlation between the local control of the tumour and the survival rate. The positive local response does not necessarily mirror the survival because metastatic potential could be increased. The high-energy heating could increase the blood flow, which promotes the dissemination [33] [34] [35] and could likely produce metastases. Promotion of metastases by hyperthermia was observed in laboratory heating experiments on mammary carcinomas in $\mathrm{C} 3 \mathrm{H}$ mice [36], sarcoma in rats [37], and Yoshida tumours [38]. However, other animal experiments showed the expected behaviour: prevention of distant metastases of sarcomas [39] [40]. Non-appropriate heating was proposed as a solution in cases of failure [41]. 
However, this doubt was questioned when a recent randomized study on soft tissue osteosarcoma demonstrated that the rate of metastasis with thermoradiotherapy was similar to that seen with preoperative radiation therapy alone [42].

As early as 1996, an extensive international cooperation investigated the use of hyperthermia in breast cancer [43]. The results were again controversial. The thermo-radiotherapy had positive outcomes in the local control in comparison to radiotherapy alone; however, the survival did not improve. Another breast cancer study also showed that the local progression-free survival was better when high heat absorption was reached in combination with radiotherapy, but the survival time was lower than when radiotherapy was used alone in the same hyperthermia combinations where local control was successful [44]. Interestingly, when the local control was not carried out, the radiotherapy was overtaken by the survival rate [43]. Another similar study, however, found evidence of toxicity [45].

The problems with the survival time appeared again in the study of pelvic and abdominal cancers [46]. The four-year survival time using hyperthermia and radiotherapy treatment compared to radiotherapy alone was doubled in the case of uterine cervix carcinoma. The local control was also significantly better in the cervix study [47], and the advantage of hyperthermia was shown when the radiotherapy was not completed [47]. In a parallel trial, however, the survival benefits of rectal, and bladder malignancies were not significant [46].

Further study of uterine cervix carcinoma showed the benefit of survival [48], but the distant metastases were more than three times higher when hyperthermia was combined with radiotherapy compared to the earlier data [49]. The cervix study also showed better four-year survival when radiotherapy was used alone than when combined with hyperthermia [50]. The remission rate was better when hyperthermia was applied, but again, distant metastases increased significantly when hyperthermia was applied. The possible explanation of controversy is the missing reference point in the studies [51]. The newest cervix study [52] was inconclusive, and the study was terminated. The interim results showed, however, that the event-free survival was slightly worse in thermo-radiotherapy than in chemo-radiotherapy, but it was not statistically significant.

A prospective, randomised, controlled, multicentre phase III trial for nonsmall cell lung cancer (NSCLC) [53] showed no improvements in overall survival in the hyperthermia cohort. The appearance of distant metastases was five-times higher $(10 / 2 ; \mathrm{p}=0.07)$ in the combined treatment than when radiotherapy alone was used [53].

The newer findings show an unexpected contradiction between local control and survival-rate, which was measured using surface tumours in the extended clinical trial [54]. Interestingly, a recent study found that the local control was better when less energy was administered than was prescribed [55].

The contradictory results between local control and the survival rate are most likely caused by the dissemination of malignant cells, forming micro-, and later 


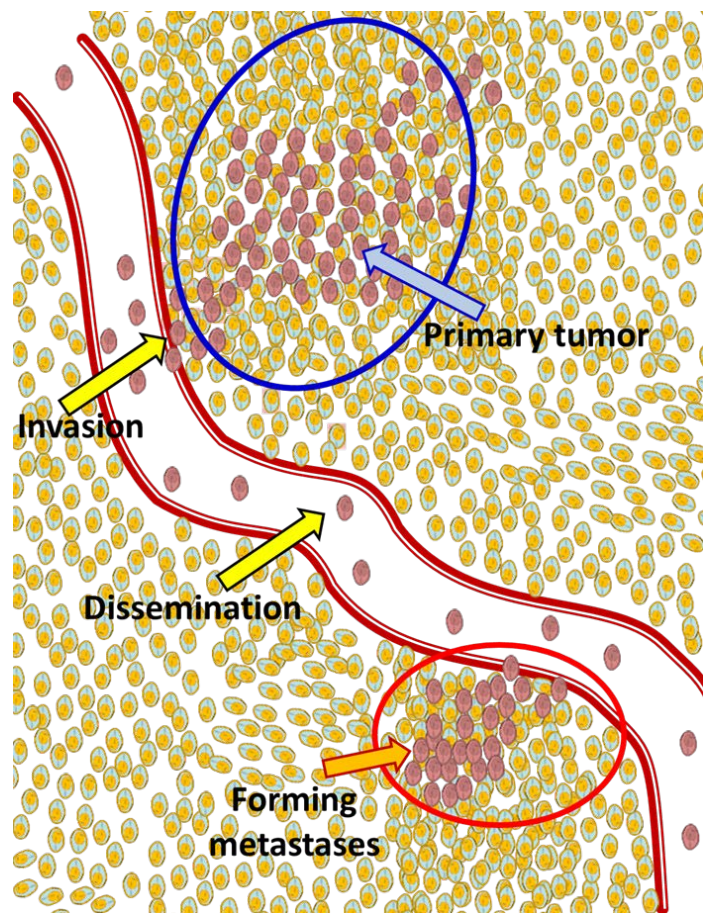

Figure 4. The local control on the primary or secondary tumour is not enough to cure the malignancy. All three stages (primer, disseminated and metastatic) of the tumour have to be considered for successful therapy.

macro-metastases. The malignancy occurs when the cells are disseminated from the tumour lesion by the various transport systems (lymph, blood), or their effect becomes systemic by one of the general mechanisms of the organism, Figure 4. Metastases are the main life-threatening process in cancer, attacking the organs that are crucial for life, e.g. the respiratory system, central nervous system, cardiovascular system, etc.

\subsection{Should Homogeneous (Isothermal) or Selective (Heterogeneous) Heating be Used?}

In the following we concentrate on the local-regional hyperthermia for curative intention. When local-regional hyperthermia is selected as a treatment, the real intention is to heat the malignant cells. The easiest way to do so is to heat the tumour as a mass, homogeneously and isothermally, with the understanding that the malignant cells will be heated as well. The challenge here is the physiological feedback. Heating a local tumour mass induces a systemic reaction to re-establish the thermal homeostasis, which increases the blood-flow through the unheated and surface cooled parts of the body to cool down the overheated blood, Figure 5.

The increased blood flow has benefits for complementary chemo- and radio-therapy, but delivers glucose and nutrients supporting the malignant metabolism and helps the invasion and dissemination of malignant cells. In fact, the increased blood flow induces an uncontrolled competition between the thermal cell death and the support of the malignant effects. 


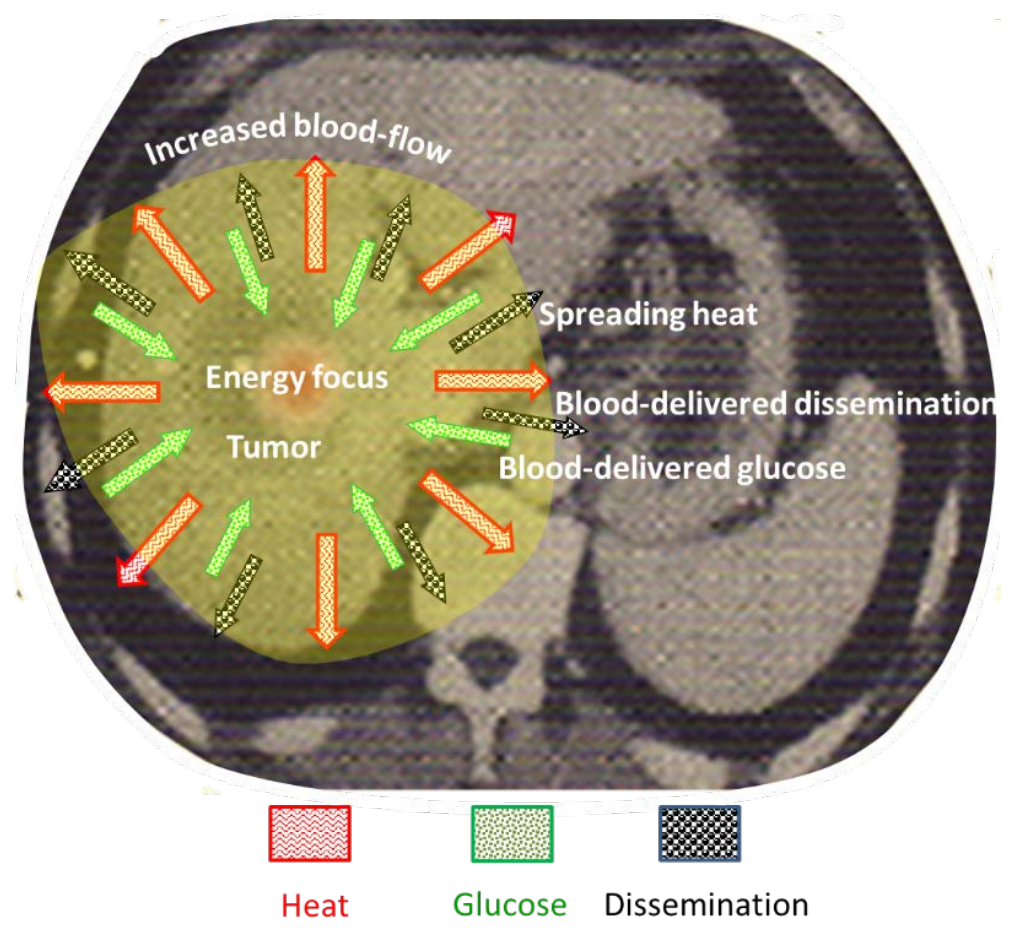

Figure 5. The focused energy on the tumour does not focus the temperature, which spreads by elapsed time. The local spreading of heat intensifies the blood flow, which is a positive effect for complementary therapies, but supports extra nutrients and increases the risk of dissemination of the malignant cells.

The challenge is exposing the malignant cells to high heat, while only exposing the tumour to moderate heat?

Consequently, to avoid the uncontrolled physiological feedbacks, there are two possible strategies:

1) Use a very short heating time to avoid feedback, since the physiological feedback develops in its full scale within minutes. When the volume of action shrinks, the necessary power lowers, and despite the high power-density, no immediate physiologic feedback is induced. This type of treatment is local enough to fulfil the requested conditions.

2) When heating larger volumes, longer heating times is necessary, due to the relatively lower density of the power in depth avoiding safety risk. In this case, the solution could be to produce lower temperatures. This mild temperature could be enough to induce and sensitize the complementary therapies, but not enough to produce any specific hyperthermia. The solution, in this case, could be to use completely heterogenic heating, where tiny particles connected to the malignant cells are heated to high temperature, but preferably do not absorb heat in the entire mass of the tumour. This solution requires specific targeting and selection of the chosen particles, Figure 6.

To carry out these two strategies, we can (1) insert artificial nanoparticles into the tumour, which have selection ability, using binding antigens for example, or (2) choose a readily available nanoparticle that is specifically connected to the malignant cells. 

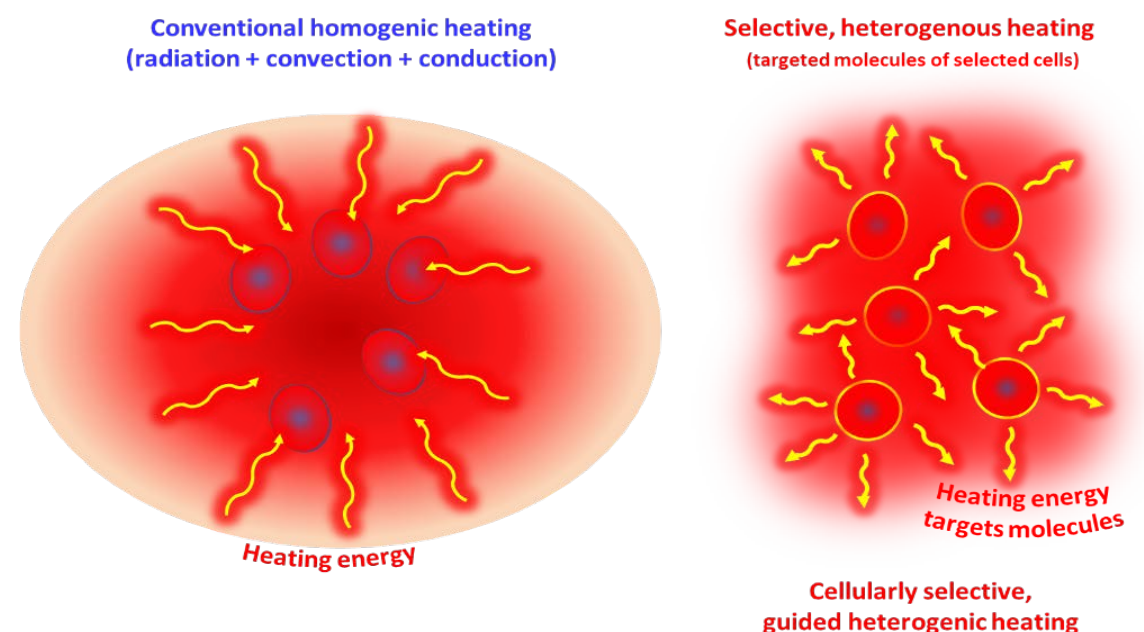

Figure 6. Conventional heating targets the complete mass of the tumour, while the selective treatment targets multiple, small parts.

\subsection{Necrosis or Apoptosis?}

The original idea of hyperthermia was to kill the cells by necrotic way; and so, necrosis was studied to determine the dosing of hyperthermia [56] [57]. The cumulative equivalent minutes (CEM) were defined by necrosis and calibrated by an in vitro cell culture measurement. The calibration point was set at $43^{\circ} \mathrm{C}$, and the aim was isothermal temperature distribution in the target by the location and time of treatment. The complete dose unit for the necrosis reference is $\mathrm{CEM} 43^{\circ} \mathrm{CTx}$, and is measured in minutes. The time-temperature relationship on which this conversion is based was suggested by many experimental observations of different biological systems based on specific thermal injury [58] [59]. $\mathrm{CEM} 43^{\circ} \mathrm{CTx}$ was introduced as the dose in clinical applications. The basic point of $\mathrm{CEM} 43^{\circ} \mathrm{CTx}$ was the $\mathrm{CEM} 43^{\circ} \mathrm{CT} 100$ (complete homogeneity was achieved at $\mathrm{T}=43^{\circ} \mathrm{C}$ ), where the measured Chinese hamster cell line in vitro was necrotized completely over a period of 200 minutes. In real cases however, necrosis was not reached because the temperature was not high enough or the time necessary to achieve the actual dose for necrosis was too long. Clinical hyperthermia works below $43^{\circ} \mathrm{C}[60]$, so the necrosis was not necessary for a correct dose.

In most of the clinical applications, the temperature does not exceed $43^{\circ} \mathrm{C}$ and is no longer than $120 \mathrm{~min}$. This means that the necrosis (which is the basic reference) is only partially responsible for cell death, and a portion of the cells are dying as a result of apoptosis. There are various possible ways for cells to die, including necrosis, apoptosis, or autophagy, which have many variations of their "mixture", called necroptosis, aptonecrosis, etc. [61]. These processes could occur on very different time-scales depending on their regulatory pathways, and the regulation of necrotic cell death may be complex [62].

The real cell death mechanism depends on heating of the target. For necrosis, a high local energy is necessary for the entire cell, while apoptosis in complete cell heating mostly uses intrinsic signal pathways. The selective heating of the membrane will stimulate the external apoptotic signals, Figure 7. 


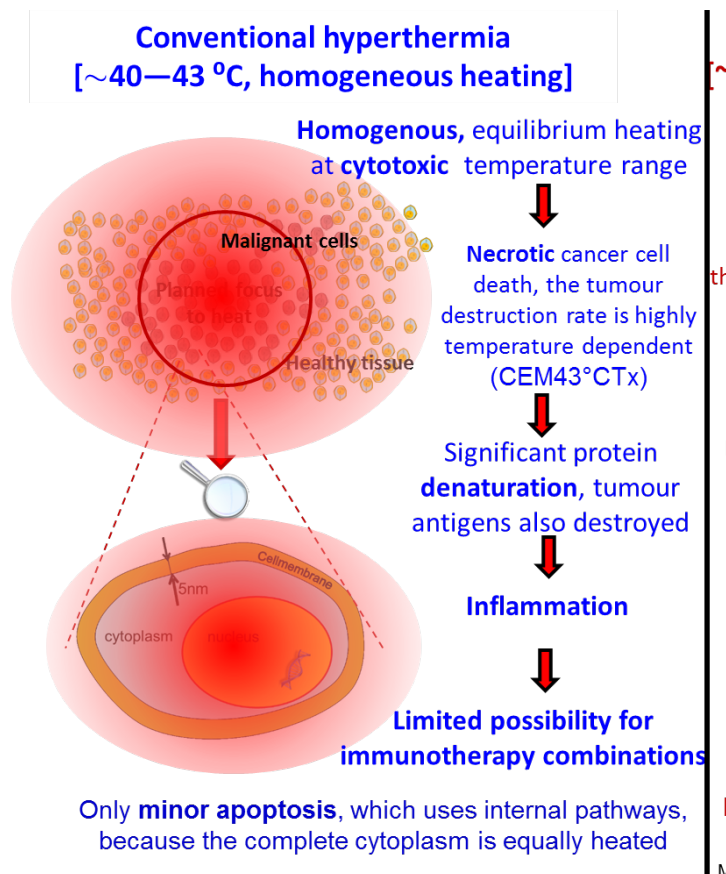

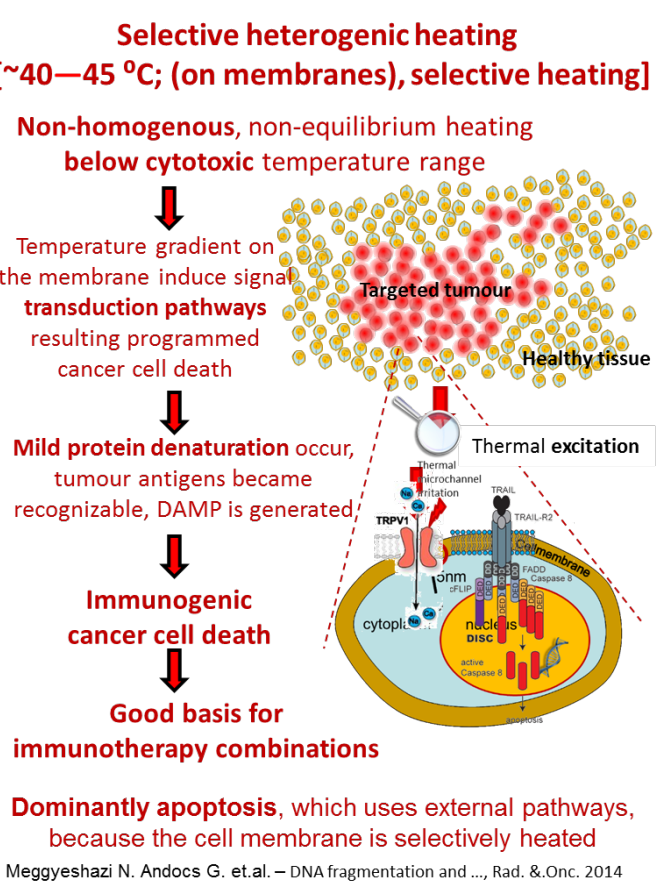

Figure 7. The isothermal heating of conventional hyperthermia differs from selective hyperthermia by their actions.

\subsection{What Is the Dose?}

The dosing problem is one of the main barriers to wide clinical acceptance [63]. The proper dosing must be easily applicable and reliable to measure in standard hospital conditions. Presently, the CEM $43^{\circ} \mathrm{CTx}$ dose concept [64] is devoted to measuring and comparing the treatment doses. It is based on in vitro experiments [65] with necrotic references at $43^{\circ} \mathrm{C}$. It does not count the long-time apoptotic effects, but only mimics the necrosis, which is the parameter for local control. Furthermore, it is too complicated and sometimes irrelevant [66], and it does not frequently correlate with the clinical observations [67] [68]. The complex interactions and cell-destroying mechanisms request the extension of the dose, including the apoptosis, necrosis, and necroptosis. The extended, generalized dose has been introduced [69].

Measuring the absorbed heat is almost impossible using standard conditions, so information about the absorbed heat is acquired by measuring the temperature. However, the measurements should describe a map of the distribution, which requires many points of measurement in the tumour.

Measuring the temperature in depth is a complicated task. The invasive measurement has huge disadvantages: it could have various side effects and one single sensor point is not enough to characterize the temperature of the heterogeneous target, Figure 8.

The repeated heating requires repeated invasive measurements, which increase the risk. Furthermore, the hot-spots outside of the target have to be measured too, which requires temperature measurements in unidentified locations. Measuring the temperatures in lumens or cavities near the tumour is not 


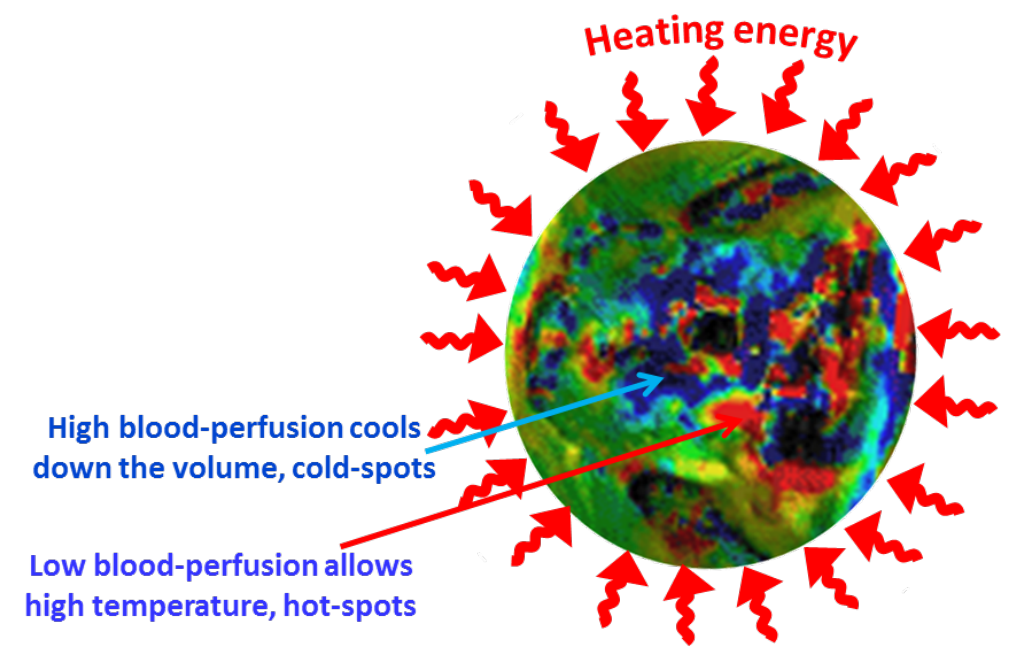

Figure 8. The heated target is very heterogeneous. Despite the homogeneous heating, the temperature will be non-homogeneous, presenting hot and cold-spots in the targeted volume.

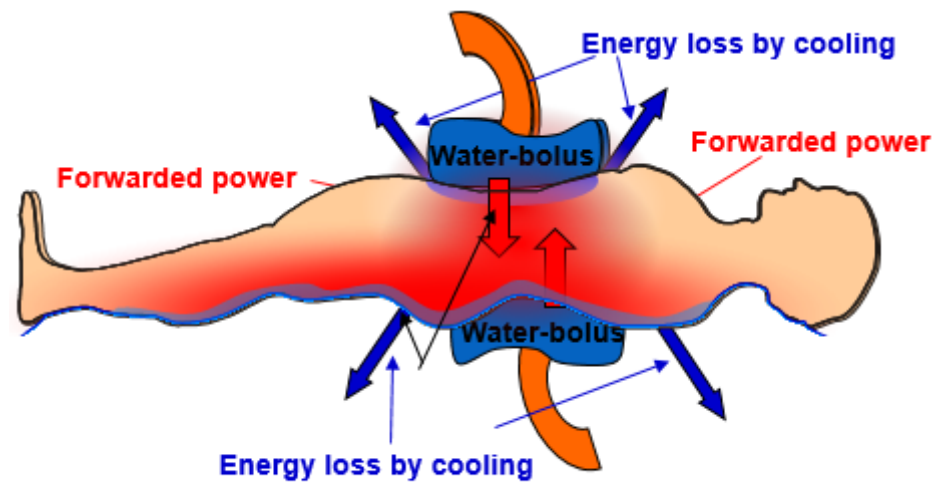

Intensive cooling to avoid the burn on skin

Figure 9. Energy loss is uncontrolled when intensive surface cooling is applied. Cooling loses energy and the uncontrolled loss of energy blocks the normal dosing.

enough, and not directly measuring the tumour temperature could affect the treatment. The lumen has much less "cooling" blood flow than does the tumour, so the same energy absorption heats the intraluminal probe to a higher temperature, and there is no guarantee that the lumen is heated on the same energy flux (SAR) as the tumour. We focus our transmitted energy on the tumour and not on its distant neighbourhood, so the measurement of this type will be inaccurate, measuring the heat-conductive behaviour of the surrounding tissue.

Introducing the well-known SAR parameter (like in radiation therapy, Gy = $\mathrm{J} / \mathrm{kg}$ ) would be a practical dose option; however, the intensive surface cooling inhibits this idea because the energy, which is taken away by cooling, is missing from the dose, Figure 9. To solve the challenge of the dose, we must reduce the uncontrolled loss of the provided heat, and be sure that the vast majority of the provided bioelectromagnetic energy absorbs as heat in the targeted malignant cells. In this case, the incoming energy could be the dose of the actual effects of hyperthermia. 


\subsection{Thermal Cell Death or Thermally-Assisted Cell Death?}

Our original reasoning for heat-treating tumours was the higher thermal sensitivity of cancer cells compared to healthy cells, but the situation is more complex. The microenvironment of the tumour cells, the hypoxia, the angiogenesis and many other factors could modify the outcome of heat treatment. In many cases, thermal necrosis acts directly; however, at lower temperatures, time-consuming cell death processes, including various kinds of apoptosis, occur in addition to necrosis (direct thermal cell death). This is not thermal cell death directly but thermally-assisted cell death. The appropriate thermal action induces these changes in the heated region. Thermal action is defined by the absorbed heat energy, which produces temperature and structural variations in the target. The proper structural changes lead to a series of molecular interactions and apoptosis, while providing information about the cancer to the immune system.

\subsection{Preciosity of Selection}

The selection is a crucial point of local hyperthermia. In the case of invasive applications (like ablation), the selection is mostly made by image-guiding performed by an interventional radiologist. Regarding non-invasive treatments, the properties of the electromagnetic effects must be used for selection.

One of the ways to make the selection is to use artificial focusing, which is also based on imaging localization. The focusing is very similar to the ionizing radiation, using electromagnetic waves/fields on geometrically defined points outside of the body but targeting the image-determined focus. The problems here are simply technical. The radiation and their interferences may produce hot-spots in the body, and the robust inhomogeneity (tissues, transports, electrolytes, membranes, etc.) modifies the result of focusing massively. In addition to the inhomogeneities, the induced blood-flow and its physiological (and not technical) regulation mean the focusing is not controlled enough, and the absorbed heat in the target could produce different temperature increases due to the transports moving in/out of the target.

The dose, in this case, must be connected to the temperature measured in the target since, due to the physiological regulation of cooling, the absorbed energy will not be indicative of the dose. The natural and non-linearly increased transport (mainly blood-flow) in the heated target removes a portion of the energy, so only the measured temperature could provide information about the heating of the target. Furthermore, due to the interferences and the target inhomogeneity, the uncontrolled hot-spots could be created outside the target, which must be controlled as well. The control of hot-spots could be performed with temperature measurement only.

When we apply nanoparticle heating, the selection is accurate and the energy loss is negligible because the induced transport by physiologic feedback is small. However, when the nanoparticles are highly heated, they can heat the entire mass around them, which leads to an uncontrolled situation. The solution is to heat up the malignant cells using connected nanoparticles (selectively connected 


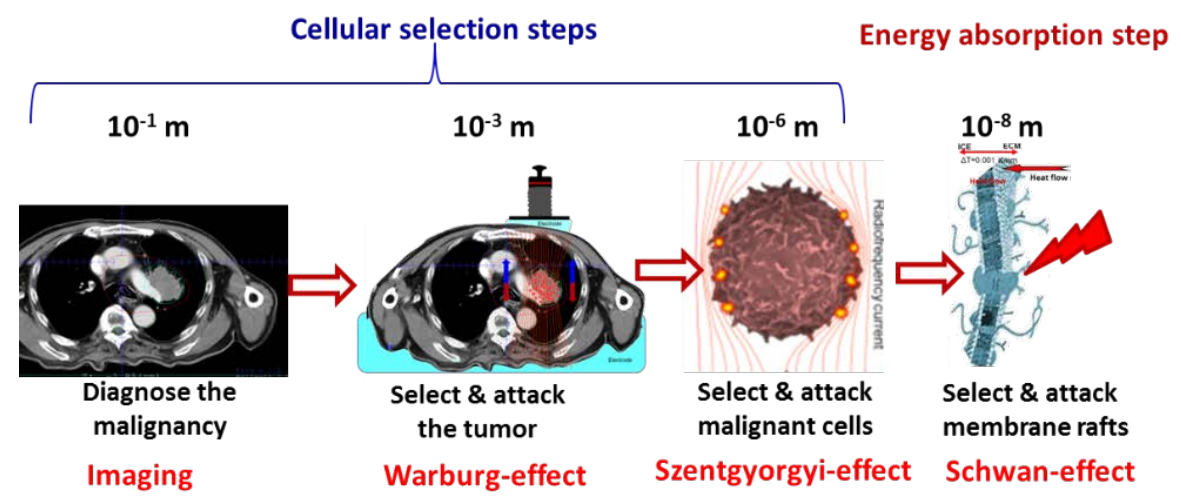

Figure 10. Precise heating selection. The heated targets are the nano-clusters (rafts).

only to the cancer cells), and use the thermal initialization to eliminate them, while not delivering more energy than necessary, Figure 10.

\subsection{The Simulation and Planning}

Software with the appropriate calculation of bioelectric interactions could be a way to simulate and plan the treatment. This could be performed using a method similar to ionizing radiation. Professionals could calculate the plan, and from this, the temperature could be estimated. Some sophisticated model calculations were made to calculate the energy absorption and the developed temperature in the deep-seated tumours [70] [71] [72].

However, the simulation of hyperthermia differs entirely from the simulation of ionizing radiation:

1) Ionizing radiation has high energy, and its path in the body could be easily calculated.

2) Ionizing radiation has a short-time treatment. During this time the physiology shows no changes, and the conditions do not vary from the preliminarily calculations.

3) The beam of ionizing radiation could be sharp enough to calculate the geometry of its targeted structure.

4) The temperature in ionizing radiation treatment is a particular side effect, which should be avoided.

These above points are not valid for hyperthermia.

1) The hyperthermia energy is not ionizing, so the radiation path requires more complicated calculations, based on Maxwellian equations.

2) It is a long-time treatment. The increasing temperature will increase the physiological feedback non-linearly, which modifies the heat-exchange in the target [73]. The simulations were calculated with Pennes equation, using a constant perfusion rate, which is not the case. The non-linear feedback modifies the perfusion, it is variable between individuals, and it depends on the location of the tumour, the stage, the angiogenetic status, and even on the psychological state of the patient. In fact, these parameters are not calculable, can only be determined during the actual treatment and have no connection to the simulation and planning. The planning calculates stable conditions 
during the treatment, which leads to a complete misuse of the information.

3) The electromagnetic waves or fields are not definite beams. These are wide beams, and not able to be calculated from geometric structures.

4) In the case of hyperthermia, the temperature is the aim of the simulation. While in ionizing simulations the iso-dose characterizes the area, which will have equal (or similar) molecular changes (mainly breaks of the strands of DNA) and the temperature plays no role in the effect. In hyperthermia, the expected molecular changes are complex, and the temperature initializes the complex action.

5) Hyperthermia must be adaptive for the patient. The long treatment time could lead to many complaints, which have to be taken into consideration, irrespective of what the planning had calculated.

\subsection{Local Tumour Destruction or Systemic Action against Malignancy?}

The malignancy is systemic, due to the invasion of the malignant cells to the transport systems, and the disseminated cells form metastases. The metastases drastically lower the survival time and the quality of life of the patient. Consequently, a systemic treatment is necessary to target the spread of malignant cells and distant metastases. As described, WBH was not able to fulfil this task completely and is a controversial method.

The local tumour destruction can lead to systemic action against malignancy by the tumour-specific immune reaction. The challenge is how to manage the immune response [74], when we know that the general immune system is not able to recognise the tumour. The key for the liberated tumour antigens to become the core information for antigen-presenting cells [75]. The method of mEHT acts in an integrative way compared to other hyperthermia methods [76]. The main clinical achievement is the abscopal effect, which is the concept of "treating locally, acting globally", Figure 11.

\subsection{Do the Heating Techniques Make a Difference?}

The heating techniques determine the result of the clinical treatment. Like the categories of chemotherapy or radiotherapy, which include many different treatments, "hyperthermia" is also a large category with different technical aspects. We have seen that exposing the tumour to $42^{\circ} \mathrm{C}$ in WBH has entirely different results than the same temperature in any local treatment. Characterization of the temperature alone is not enough to categorize the technical solutions.

In many experimental models, a water bath is used to achieve hyperthermia, which does not model the various electromagnetic technical solutions. The various electromagnetic heating technologies also have their specialties, which are determined by the bioelectromagnetic action of the technology. In the evaluation of the applied technique, the kind of energy delivery, the method of heat absorption and the handling of the physiological reactions and inhomogeneities of the target tumour are taken into consideration. The absorbed energy of the target 


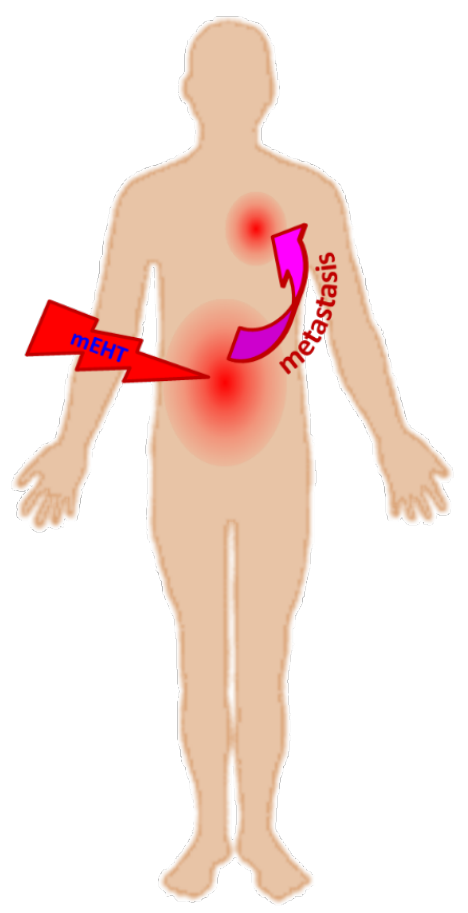

Figure 11. The abscopal effect extends the loco-regional hyperthermia to systemic hyperthermia when the treatment of the local primer tumour also acts on distant metastases.

and its temperature distribution are not the same [77], and they are largely determined by the blood-flow. The technical solutions must handle the challenge of how the provided energy will be transformed to the useful temperature.

\subsection{Change of the Paradigm in Oncology}

Nowadays, the oncology field is working toward changing its paradigm. The stem-cell theory and the various considerations of the cause of cancer, taking into account the microenvironment and multiple biological factors, changes the old paradigm of a single "renegade cell", how cancer begins [78]. In the clinic, the idea of "integrative medicine" suggests that the whole patient must be treated in an integrative manner, not only by considering the localized disease. The slogan is clear: "treat the patients with the tumour, and not the tumour alone." We have to consider the complete patient status and concentrate on survival time together with the acceptable quality of life instead of focusing on local control and other local parameters. This trend was recognized, even amongst bigpharma companies, when the change of paradigm started [79], and personalized medicine is a direct consequence of this idea. The new thinking also changed the evaluation of evidence. The local control became the secondary parameter, behind survival and quality of life.

The change of this paradigm led to a question: where did medicine go wrong? [80]. The answer is a result of complexity being neglected, despite the fact that "disease is not a loss of regularity, but the loss of complexity" [80]. Einstein noted [17]: "we cannot solve problems by using the same kind of thinking we used when we created them". The problem is that the locally heated body part 
protects itself against the temperature increase, and physiologic feedback begins to cool the overheated area. Then, the increased blood flow delivers more nutrients and supports tumour growth. Uncontrolled competition starts between the thermal cell distortion and active support of tumour growth, accompanied by the risk of increased dissemination of malignant cells. We have to consider the physiological complexity of this process. The trends and perspectives should provide a new way of thinking about cancer and its general treatment, including hyperthermia.

Research concentrating on the evolution of the products of disease is not enough; the evolutional process has to be targeted [79]. The cause of cancer is intensively debated and has complex approaches [81], but the field of immune-oncology is a new revolutionary change to oncological thinking.

We may approach the question of the regulation the evolutionary processes of cancer development from the defence system of the organism. Naturally, the question of the immune activity in heated tissues was also studied [82]. Decreased activity of natural killer cells (NK) was observed at higher temperatures in in vivo models [83], which could also be a reason for increased metastasis [84] [85] after heat therapies. The activity of NK cells sharply decreases over $40^{\circ} \mathrm{C}$ in humans [86] [87], and the temperature limit for immune activation is under $40^{\circ} \mathrm{C}$ [88]. By considering immune therapies, a new strategy for hyperthermia can emerge [89]. The importance of immune-stimuli in conjunction with hyperthermia was shown in the early clinical study of pancreatic cancer when patients stimulated with granulocyte-monocyte colony stimulation factors (GMCSF) were living longer despite their distant metastases [90]. The expected effect of the immune-modulation is the abscopal response. It consists of a tumour regression at other anatomic sites following curative heating of the primary tumour.

A comprehensive book was published recently addressing tumour-ablation (high-temperature hyperthermia in a well-localized spot) as support of anti-tumour immunity [91].

A large number of hyperthermia articles devoted to immune effects of hyperthermia have also been published [92]-[102].

\subsection{Modulated Electro-Hyperthermia (mEHT)}

In order to change the heating paradigm, we have to target only the malignant cells only, selecting them based on their specific biophysical behaviour. mEHT is selective (heterogeneous) [103] [104], and it keeps the dynamic equilibrium in homeostasis [29], which is the main strategic concept of the treatment.

The selectivity induces physiologic feedback (blood-flow) to complementary applications [105], but not as much as it promotes dissemination, which is consequently able to increase the survival time [106] [107].

This approach differs from other hyperthermia methods [76], and shows nanoscopic heating using transmembrane clusters of proteins (membrane rafts) and heating selectively at high temperatures [108]. This nano-heating technolo- 
gy has been studied theoretically [109] and experimentally [110]. The theoretical model of the intracellular changes due to the electric field effect as the consequence of the membrane raft heating has also been reported [119]. Heating in the nanoscale range has been reviewed [103], and emphasizes the electromagnetic specialty of the method [112].

mEHT has a certain synergy between temperature and the electric field [113], producing better results at the same temperature than conventional hyperthermia. mEHT causes apoptosis [114] [115] [116], which is initialized in the membrane of malignant cells [117]. This process starts with a high temperature in the clusters of transmembrane proteins (membrane rafts) on the surface of the membrane. Due to the excitation of the external apoptotic signals (TRAIL-DR5, FADD, FAS $\rightarrow$ Cleaved Caspase $3 \rightarrow$ apoptosis, Figure 12.) immunogenic cell-death is produced with the assistance of the damage-associated molecular pattern, including a significant expression of HSPs on the membrane of malignant cells and in their extracellular matrix [118].

The localized energy intake excited the external apoptosis signal producing a
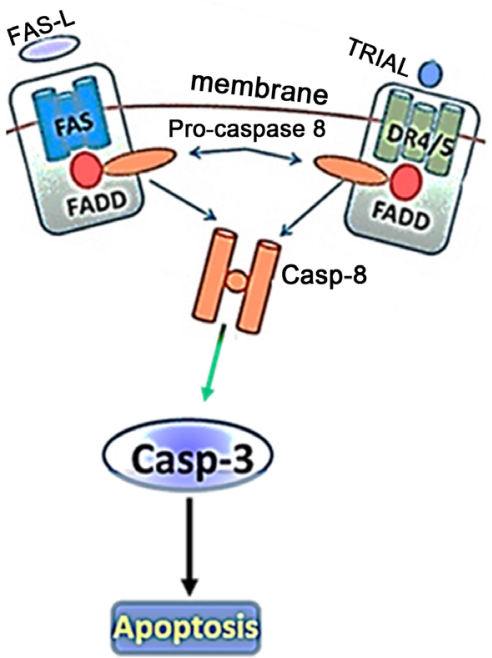
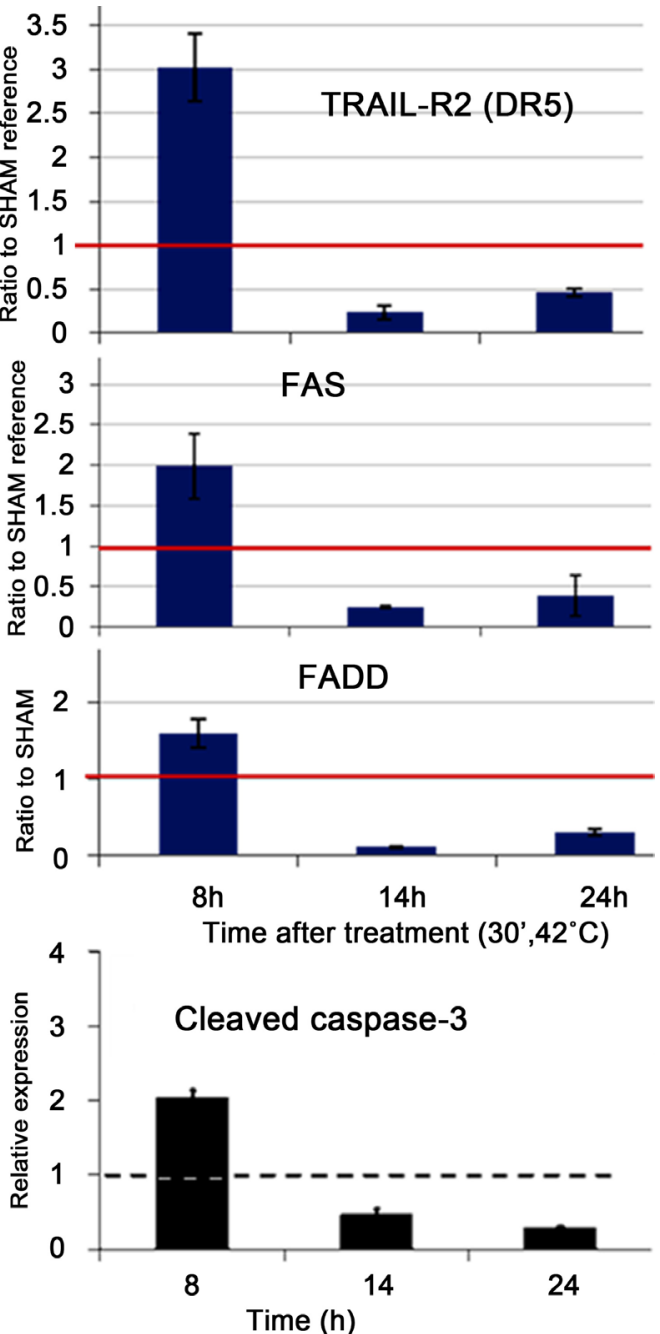

Figure 12. The active cell death mechanism involves apoptosis with the external signal pathway in the case of mEHT. 


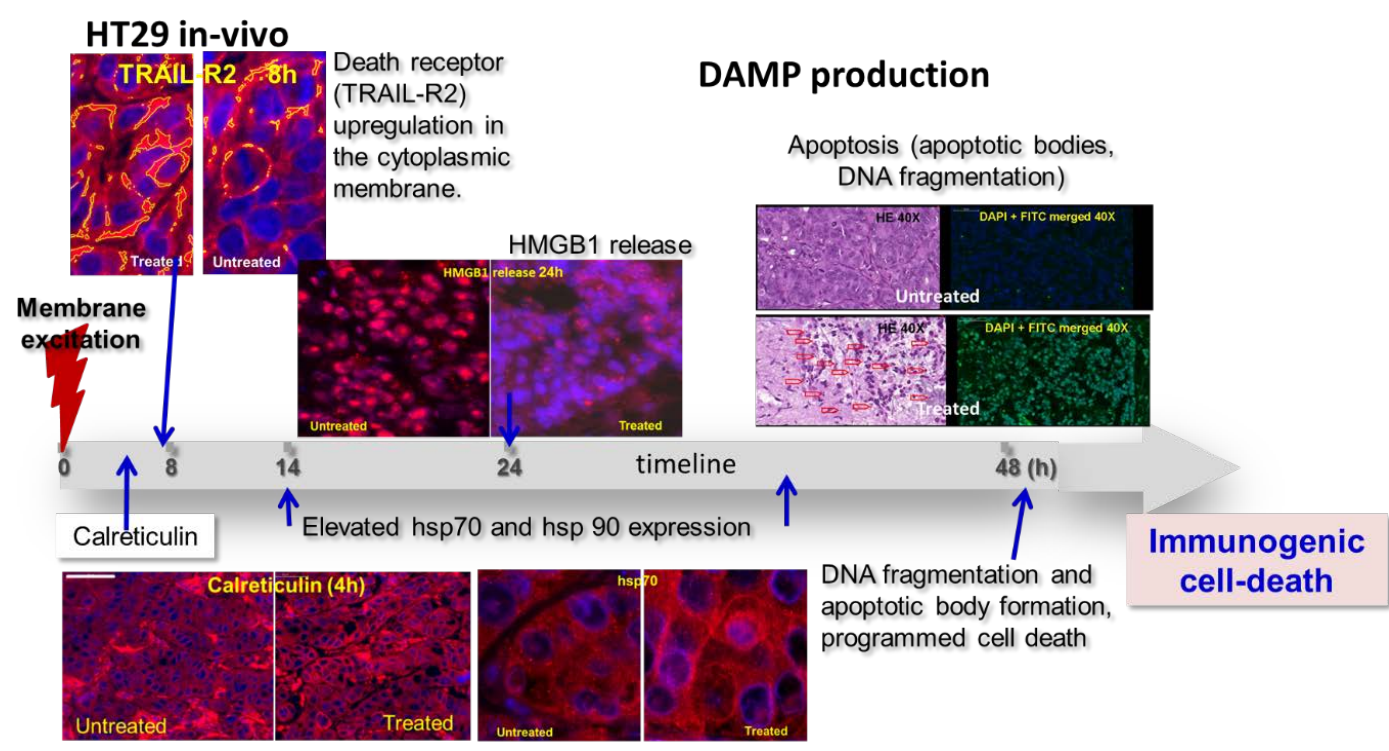

Figure 13. The apoptotic process of mEHT produces a typical damage-associated molecular pattern and, consequently, immunogenic cell death.

branch of particular molecules. HSP70 is expressed on the membrane and extracellularly liberated [119] HMGB1, calreticulin, and small vehicles like apoptotic bodies and exosomes are involved. These are members of the damage-associated molecular pattern, which could play an immunogenic role in the further development of complexity [120]. The mechanism involves destroying the malignant cells by $\mathrm{mEHT}$, using immunogenic cell death as the basis of the immune effects, Figure 13.

Due to the immune processes, strong abscopal effects can be observed [121], working like a tumour vaccination, that do not allow the tumour to redevelop [122].

The dosing could also help generalized [69], and the high efficacy of the local heating [123] of mEHT was clearly shown. The path from laboratory experiments to clinical applications is documented [126], and numerous clinical studies using the method have been published [127]. There have been several case reports for various advanced cases, mostly when conventional methods failed [126]-[132].

Clinical studies were performed for brain gliomas [133] [134] [135] [136], for lung cancers [107] [137], and for gastrointestinal tumours [138] [139] [140], [141] [142].

The results of treating sarcomas with mEHT [143] [144], as well as various other malignant diseases [145] [146], are published together with overviews [147] [148] [149]. Monographs were released on the topic of mEHT [30] [150] [151].

\section{Conclusion}

We are firmly convinced that hyperthermia has opened new therapeutic possibilities in oncology and has become the fourth column of oncotherapy world- 
wide. There are also many answers to the common questions about using hyperthermia. We need precise selection of what to heat, taking into account the homeostatic feedback mechanisms of the body. The specific selectivity has to concentrate on the malignant cells individually, and thermally activate their special necrosis or apoptosis, allowing for antigen presentation from the malignant cells and activating the mechanisms of the tumour-specific immune response in the whole body. The activated immune system performs the local treatment systemically, forming tumour-specific immune responses, which could function similarly to tumour vaccination. The endpoint of the therapeutic application of hyperthermia has to be improved survival time and quality of life, while the tumour regression (local control) is an extra advantage.

This article is devoted to the memory of Dr. Gian Franco Baronzio.

\section{References}

[1] Hornbach, N.B. (1987) Is the Community Radiation Oncologist Ready for Clinical Hyperthermia? Radiographics, 7, 139-141. https://doi.org/10.1148/radiographics.7.1.3329357

[2] Oleson, J.R. (1991) Progress in Hyperthermia? International Journal of Radiation Oncology, Biology, Physics, 20, 1147-1164. https://doi.org/10.1016/0360-3016(91)90218-S

[3] Smythe, W.R. and Mansfield, P.F. (2003) Hyperthermia: Has Its Time Come? Annals of Surgical Oncology, 10, 210-212. https://doi.org/10.1245/ASO.2003.02.011

[4] Van, Z.K. (2002) Heating the Patient: A Promising Approach? Annals of Oncology, 13, 1173-1184. https://doi.org/10.1093/annonc/mdf280

[5] Roussakow, S. (2013) The History of Hyperthermia Rise and Decline. Conference Papers in Medicine, 2013, Article ID: 201671. https://doi.org/10.1155/2013/428027

[6] Bath, C. (2014) Using Hyperthermia for Cancer Treatment: Proofs, Promises, and Uncertainties. ASCO Post, New York.

[7] Ota, S., Yamazaki, N., Tomitaka, A., Yamada, T. and Takemura, Y. (2014) Hyperthermia Using Antibody-Conjugated Magnetic Nanoparticles and Its Enhanced Effect with Cryptotanshinone. Nanomaterials, 4, 319-330. https://doi.org/10.3390/nano4020319

[8] Perche, F. and Torchilin, V.P. (2013) Recent Trends in Multifunctional Liposomal Nanocarriers for Enhanced Tumour Targeting. Journal of Drug Delivery, 2013, Article ID: 705265.

[9] Pranali, P., Deshpande, B.S. and Torchilin, V.P. (2013) Current Trends in the Use of Liposomes for Tumour Targeting. Nanomedicine, 8, 1509-1528.

https://doi.org/10.2217/nnm.13.118

[10] Mackie, T.R. (2006) History of Tomotherapy. Physics in Medicine and Biology, 51, R427-R453. https://doi.org/10.1088/0031-9155/51/13/r24

[11] Levin, W.P., Kooy, H., Loeffler, J.S. and DeLaney, T.F. (2005) Proton Beam Therapy. British Journal of Cancer, 93, 849-854. https://doi.org/10.1038/sj.bjc.6602754

[12] Maggiorella, L., Barouch, G., Devaux, C., Pottier, A., Deutsch, E., Bourhis, J., Borghi, E. and Levy, L. (2012) Nanoscale Radiotherapy with Hafnium Oxide Nanoparticles. Future Oncology, 8, 1167-1181. https://doi.org/10.2217/fon.12.96

[13] Svaasand, L.O., Gomer, C.J. and Morinelli, E. (1990) On the Physical Rationale of Laser Induced Hyperthermia. Lasers in Medical Science, 5, 121-128. 
https://doi.org/10.1007/BF02031373

[14] Wang, S.S., Chen, J., Keltner, L., et al. (2002) New Technology for Deep Light Distribution in Tissue for Phototherapy. Cancer Journal, 8, 154-163.

https://doi.org/10.1097/00130404-200203000-00009

[15] Steichen, S.D., Caldorera-Moore, M. and Peppas, N.A. (2013) A Review of Current Nanoparticle and Targeting Moieties for the Delivery of Cancer Therapeutics. $E u$ ropean Journal of Pharmaceutical Sciences, 48, 416-427. https://doi.org/10.1016/j.ejps.2012.12.006

[16] Storm, F.K. (1993) What Happened to Hyperthermia and What Is Its Current Status in Cancer Treatment? Journal of Surgical Oncology, 53, 141-143. https://doi.org/10.1002/jso.2930530302

[17] Calaprice, A. (2005) The New Quotable Einstein. Princeton University Press, Princeton.

[18] Von, A.A. and Wehner, H. (2006) Extreme Whole-Body Hyperthermia with Water-Filtered Infrared-A Radiation. In: Baronzio, G. and Hager, E.D., Eds., Hyperthermia in Cancer Treatment. A Primer, Springer, Dordrecht, 237-246.

[19] Suvernev, A.V., Ivanov, G.V., Efremov, A.V. and Ycgervov, R. (2006) Whole-Body Hyperthermia at $43.5^{\circ} \mathrm{C}-44^{\circ} \mathrm{C}$ : Dream of Reality? In: Baronzio, G. and Hager, E.D., Eds., Hyperthermia in Cancer Treatment: A Primer, Springer, Dordrecht, 227-236. https://doi.org/10.1007/978-0-387-33441-7_18

[20] Thrall, D.E., Prescott, D.M., Samulski, T.V., et al. (1996) Radiation plus Local Hyperthermia versus Radiation plus the Combination of Local and Whole-Body Hyperthermia in Canine Sarcomas. International Journal of Radiation Oncology, Biology, Physics, 34, 1087-1096. https://doi.org/10.1016/0360-3016(95)02260-0

[21] Bakhshandeh, A., Wiedemann, G., Zabel, P., et al. (2004) Randomized Trial with Ice (Ifosfamide, Carboplatin, Etoposide) plus Whole Body Hyperthermia versus Ice Chemotherapy for Malignant Pleural Mesothelioma. Journal of Clinical Oncology, 22, 7288. https://doi.org/10.1200/jco.2004.22.14_suppl.7288

[22] Hildebrandt, B., Drager, J., Kerner, T., et al. (2004) Whole-Body Hyperthermia in the Scope of Von Ardenne's Systemic Cancer Multistep Therapy (SCMT) Combined with Chemotherapy in Patients with Metastatic Colorectal Cancer: A Phase I/Ii Study. International Journal of Hyperthermia, 20, 317-333. https://doi.org/10.1080/02656730310001637316

[23] Lord, P.F., Kapp, D.S. and Morrow, D. (1981) Increased Skeletal Metastases of Spontaneous Canine Osteosarcoma after Fractionated Systemic Hyperthermia and Local X-Irradiation. Cancer Research, 41, 4331-4334.

[24] Rice, L., Urano, M., Chu, A. and Suit, H.D. (1979) The Influence of Whole Body Hyperthermia on the Frequency of Metastasis in a Murine Tumour System (Abstract). Proceedings of Ann Soc Therap Radiol, New Orleans, 23-27 October 1979, 201.

[25] Hei, T.K., Hall, E.J., Kushner, S., et al. (1986) Hyperthermia Chemotherapeutic Agents and Oncogenic Transformation. International Journal of Hyperthermia, 2, 311-320. https://doi.org/10.3109/02656738609016488

[26] Komatsu, K., Miller, R.C. and Hall, E.J. (1988) The Oncogenetic Potential of a Combination of Hyperthermia and Chemotherapy. British Journal of Cancer, 57, 59-63. https://doi.org/10.1038/bjc.1988.9

[27] Miller, R.C., Roizin-Towle, L. and Komatsu, K. (1989) Interaction of Heat with $\mathrm{X}$-Rays and Cis-Platinum; Cell Lethality and Oncogenetic Transformation. International Journal of Hyperthermia, 5, 697-705. 
https://doi.org/10.3109/02656738909140494

[28] Huxley, T.H. (2011) Biogenesis and Abiogenesis. Collected Essays of Thomas $H$ Huxley, 2011, 218-250.

[29] Hegyi, G., Vincze, G.Y. and Szasz, A. (2012) On the Dynamic Equilibrium in Homeostasis. Open Journal of Biophysics, 2, 64-71. https://doi.org/10.4236/ojbiphy.2012.23009

[30] Szasz, A., Szasz, N. and Szasz, O. (2010) Oncothermia-Principles and Practices. Springer Science, Heidelberg.

[31] McChesney, G.S., Dewhirst, M.W., et al. (1992) Response of Canine Soft Tissue Sarcomas to Radiation or Radiation plus Hyperthermia: Randomized Phase II Study. International Journal of Hyperthermia, 8, 309-320. https://doi.org/10.3109/02656739209021786

[32] Sminia, P., Jansen, W., Haveman, J., et al. (1990) Incidence of Tumours in the Cervical Region of the Rat after Treatment with Radiation and Hyperthermia. International Journal of Radiation Oncology, 57, 425-436.

[33] Oliveira, R.S., Bevilacqua, F.R.G. and Chammas, R. (1997) Hyperthermia Increases the Metastatic Potential of Murine Melanoma. Brazilian Journal of Medical and Biological Research, 30, 941-945. https://doi.org/10.1590/S0100-879X1997000800005

[34] Shah, S.A., Jain, R.K. and Finney, P.L. (1983) Enhanced Metastasis Formation by Combined Hyperthermia and Hyperglycemia in Rats Bearing Walker 256 Carcinosarcoma. Cancer Letters, 19, 317-323. https://doi.org/10.1016/0304-3835(83)90101-5

[35] Nathanson, S.D., Nelson, L., Anaya, P., Havstad, S. and Hetzel, F.W. (1991) Development of Lymph Node and Pulmonary Metastases after Local Irradiation and Hyperthermia of Footpad Melanomas. Clinical \& Experimental Metastasis, 9, 377-392. https://doi.org/10.1007/BF01769357

[36] Walker, A., McCallum, H.M., Wheldon, T.E., et al. (1978) Promotion of Metastasis of $\mathrm{C} 3 \mathrm{H}$ Mouse Mammary Carcinoma by Local Hyperthermia. British Journal of Cancer, 38, 561-563. https://doi.org/10.1038/bjc.1978.246

[37] Dickson, J.A. and Ellis, H.A. (1976) The Influence of Tumour Volume and the Degree of Heating on the Response of the Solid Yoshida Sarcoma to Hyperthermia. Cancer Research, 36, 1188-1195.

[38] Dickson, J.A. and Ellis, H.A. (1974) Stimulation of Tumour Cell Dissemination by Raised Temperature $\left(42^{\circ} \mathrm{C}\right)$ in Rats with Transplanted Yoshida Tumours. Nature, 248, 354. https://doi.org/10.1038/248354a0

[39] Hahn, E.W., Alfiery, A.A. and Kim, J.H. (1979) The Significance of Local Tumour Hyperthermia/Radiation on the Production of Disseminated Disease. International Journal of Radiation Oncology, Biology, Physics, 5, 819-823. https://doi.org/10.1016/0360-3016(79)90066-X

[40] Ando, K., Urano, M., Kenton, L., et al. (1987) Effect of Thermo-Chemotherapy on the Development of Spontaneous Lung Metastases. International Journal of Hyperthermia, 3, 453-458. https://doi.org/10.3109/02656738709140415

[41] Shah, S. (1986) Metastasis and Hyperthermia. In: Anghileri, L. and Robert, J., Eds., Hyperthermia in Cancer Treatment, CRC Press, Boca Raton, 191-227.

[42] Prosnitz, L.R., Maguire, P., Anderson, J.M., et al. (1999) The Treatment of High Grade Soft Tissue Sarcomas with Preoperative Thermoradiotherapy. International Journal of Radiation Oncology, Biology, Physics, 45, 941-949. https://doi.org/10.1016/S0360-3016(99)00272-2

[43] Vernon, C.C., Hand, J.W., Field, S.B., et al. (1996) Radiotherapy with or without 
Hyperthermia in the Treatment of Superficial Localized Breast Cancer: Results from Five Randomized Controlled Trials. International Journal of Radiation Oncology, Biology, Physics, 35, 731-744. https://doi.org/10.1016/0360-3016(96)00154-X

[44] Sherar, M., Liu, F.F., Pintilie, M., et al. (1997) Relationship between Thermal Dose and Outcome in Thermoradiotherapy Treatments for Superficial Recurrences of Breast Cancer: Data from a Phase III Trial. International Journal of Radiation Oncology, Biology, Physics, 39, 371-380.

https://doi.org/10.1016/S0360-3016(97)00333-7

[45] Emami, B., Scott, C., Perez, C.A., et al. (1996) Phase III Study of Interstitial Thermoradiotherapy Compared with Interstitial Radiotherapy Alone in the Treatment of Recurrent or Persistent Human Tumours: A Prospectively Controlled Randomized Study by the Radiation Therapy Oncology Group. International Journal of Radiation Oncology, Biology, Physics, 34, 1097-1104.

https://doi.org/10.1016/0360-3016(95)02137-X

[46] Van, Z.J., Gonzalez, G.D., Van, R.G.C., et al. (2000) Comparison of Radiotherapy Alone with Radiotherapy plus Hyperthermia in Locally Advanced Pelvic Tumours: A Prospective, Randomised, Multicentre Trial. Dutch Deep Hyperthermia Group. The Lancet, 355, 1119-1125. https://doi.org/10.1016/S0140-6736(00)02059-6

[47] Van, Z.J. and Gonzalez-Gonzalez, D. (2002) The Dutch Deep Hyperthermia Trial: Results in Cervical Cancer. International Journal of Hyperthermia, 18, 1-12. https://doi.org/10.1080/02656730110091919

[48] Harima, Y., Nagata, K., Harima, K., Ostapenko, V.V., Tanaka, Y. and Sawada, S. (2001) A Randomized Clinical Trial of Radiation Therapy versus Thermoradiotherapy in Stage IIIB Cervical Carcinoma. International Journal of Hyperthermia, 17, 97-105. https://doi.org/10.1080/02656730010001333

[49] Sharma, S., Patel, F.D., Sandhu, A.P., Gupta, B.D. and Yadav, N.S. (1989) A Prospective Randomized Study of Local Hyperthermia as a Supplement and Radiosensitiser in the Treatment of Carcinoma of the Cervix with Radiotherapy. Endocurietherapy/Hyperthermia Oncology, 5, 151-159.

[50] Vasanthan, A., Mitsumori, M., Part, J.H., et al. (2005) Regional Hyperthermia Combined with Radiotherapy for Uterine Cervical Cancers: A Multiinstitutional Prospective Randomized Trial of the International Atomic Energy Agency. International Journal of Radiation Oncology, Biology, Physics, 61, 145-153. https://doi.org/10.1016/j.ijrobp.2004.04.057

[51] Fatehi, D., Van, Z.J., Van, W.E., et al. (2006) Temperature Data Analysis for 22 Patients with Advanced Cervical Carcinoma Treated in Rotterdam Using Radiotherapy, Hyperthermia and Chemotherapy: A Reference Point Is Needed. International Journal of Hyperthermia, 22, 353-363. https://doi.org/10.1080/02656730600715796

[52] Lutgens, L.C., Koper, P.C., Jobsen, J.J., et al. (2016) Radiation Therapy Combined with Hyperthermia versus Cisplatin for Locally Advanced Cervical Cancer: Results of the Randomized RADCHOC Trial. Radiotherapy and Oncology, 120, 378-382. https://doi.org/10.1016/j.radonc.2016.02.010

[53] Mitsumori, M., Zhi-Fan, Z., Oliynychenko, P., et al. (2007) Regional Hyperthermia Combined with Radiotherapy for Locally Advanced Non-Small Cell Lung Cancers: a Multi-Institutional Prospective Randomized Trial of the International Atomic Energy Agency. International Journal of Clinical Oncology, 12, 192-198. https://doi.org/10.1007/s10147-006-0647-5

[54] Jones, E.L., Oleson, J.R. and Prosnith, L.R., et al. (2007) Randomized Trial of Hyperthermia and Radiation for Superficial Tumours. International Journal of Clinical Oncology, 23, 3079-3085. https://doi.org/10.1200/JCO.2005.05.520 
[55] Shoji, H., Motegi, M., Osawa, K., et al. (2014) Does Standardization of Radiofrequency Hyperthermia Benefit Patients with Malignancies? Annals of Cancer Research and Therapy, 22, 28-35. https://doi.org/10.4993/acrt.22.28

[56] Dewey, W.C., Hopwood, L.E., Sapareto, S.A. and Gerweck, L.E. (1997) Cellular Responses to Combinations of Hyperthermia and Radiation. Radiology, 123, $463-$ 474. https://doi.org/10.1148/123.2.463

[57] Henle, K.J. and Dethlefsen, L.A. (1980) Time-Temperature Relationships for HeatInduced Killing of Mammalian Cells. Annals of the New York Academy of Sciences, 335, 234-253. https://doi.org/10.1111/j.1749-6632.1980.tb50752.x

[58] Moritz, A.R. and Henriques, F.C. (1947) Studies of Thermal Injury. II. The Relative Importance of Time and Surface Temperature in the Causation of Cutaneous Burns. American Journal of Pathology, 23, 695-720.

[59] Henriques, F.C. (1947) Studies of Thermal Injury; The Predictability and the Significance of Thermally Induced Rate Processes Leading to Irreversible Epidermal Injury. Archives of Pathology \& Laboratory Medicine, 43, 489-502.

[60] Fatehi, D. (2007) Technical Quality of Deep Hyperthermia Using the BSD-2000. Uitgeverij Box Press, Oisterwijk.

[61] Linkermann, A. and Green, D.R. (2014) Necroptosis. The New England Journal of Medicine, 370, 455-465. https://doi.org/10.1056/NEJMra1310050

[62] Berghe, T.V., Linkermann, A., Jouan-Lanhouet, S., Walczak, H. and Vandenabeele, P. (2014) Regulated Necrosis: The Expanding Network of Non-Apoptotic Cell Death Pathways. Nature Reviews Molecular Cell Biology, 15, 135-147.

https://doi.org/10.1038/nrm3737

[63] Jones, E., Thrall, D., Dewhirst, M.W. and Vujaskovic, Z. (2006) Prospective Thermal Dosimetry: The Key to Hyperthermia's Future. International Journal of Hyperthermia, 22, 247-253. https://doi.org/10.1080/02656730600765072

[64] Dewhirst, M.W., Viglianti, B.L., Lora-Michiels, M., et al. (2003) Basic Principles of Thermal Dosimetry and Thermal Thresholds for Tissue Damage from Hyperthermia. International Journal of Hyperthermia, 19, 267-294. https://doi.org/10.1080/0265673031000119006

[65] Sapareto, S.A. and Dewey, W.C. (1984) Thermal Dose Determination in Cancer Therapy. International Journal of Radiation Oncology Biology, Physics, 10, 787-800. https://doi.org/10.1016/0360-3016(84)90379-1

[66] Maquire, P.D., Samulski, T.V., Prosnitz, L.R., Jones, E.L., Rosner, G.L., Powers, B., et al. (2001) A Phase II Trial Testing the Thermal Dose Parameter CEM43 Degrees T90 as a Predictor of Response in Soft Tissue Sarcomas Treated With Pre-Operative Thermoradiotherapy. International Journal of Hyperthermia, 17, 283-290. https://doi.org/10.1080/02656730110039449

[67] Maguire, P.D., Samulski, T.V., Prosnitz, L.R., et al. (2001) A Phase LL Trial Testing the Thermal Dose Parameter CEM43 ${ }^{\circ}$ T90 as a Predictor of Response in Soft Tissue Sarcomas Treated with Pre-Operative Thermoradiotherapy. International Journal of Hyperthermia, 17, 283-290. https://doi.org/10.1080/02656730110039449

[68] Bruijne, M., Van, H.B., Van, R.G.C., et al. (2010) Evaluation of CEM43 ${ }^{\circ}$ CT90 Thermal Dose in Superficial Hyperthermia; A Retrospective Analysis. Strahlentherapie und Onkologie Journal (Radiotherapy and Oncology), 186, 436-443. https://doi.org/10.1007/s00066-010-2146-x

[69] Vincze, G.Y., Szasz, O. and Szasz, A. (2015) Generalization of the Thermal Dose of Hyperthermia in Oncology. Open Journal of Biophysics, 5, 97-114.

https://doi.org/10.4236/ojbiphy.2015.54009 
[70] Findlay, R.P. and Dimbylow, P.J. (2005) Effects of Posture on FDTD Calculations of Specific Absorption Rate in a Voxel Model Of The Human Body. Physics in Medicine and Biology, 50, 3825-3835. https://doi.org/10.1088/0031-9155/50/16/011

[71] Jianging, W., Mukaide, N. and Fujiwara, O. (2003) FTDT Calculation of Organ Resonance Characteristics in an Anatomically Based Human Model for Plane-Wave Exposure. Proceedings of Asia-Pacific Conference on Environmental Electromagnetics, 4-7 November 2003, 126-129. https://doi.org/10.1109/CEEM.2003.238647

[72] Neufeld, E. (1978) High Resolution Hyperthermia Treatment Planning. Ph.D. Thesis, Swiss Federal Institute of Technology, Zurich.

[73] Wittig, T. (2017) BioEM Simulations with CST Studio Suite. https://www.cst.com/Content/Events/Downloads/euc2014/4.2.3.pdf

[74] Szasz, A. (2013) Challenges and Solutions in Oncological Hyperthermia. Thermal Medicine, 29, 1-23. https://doi.org/10.3191/thermalmed.29.1

[75] Baronzio, G., Gramaglia, A. and Fiorentini, G. (2006) Hyperthermia and Immunity. A Brief Overview. Vivo, 20, 689-695.

[76] Yang, K.L., Huang, C.C., Chi, M.S., Chiang, H.C., Wang, Y.S., Andocs, G., et al. (2016) In Vitro Comparison of Conventional Hyperthermia and Modulated Electro-Hyperthermia. Oncotarget, 7, 84082-84092.

[77] Van, Z.J. (2005) Radiotherapy and Hyperthermia in Cervical Cancer. ESTRO/TMH Presentation, Mumbai.

[78] Weinberg, R.A. (1998) One Renegade Cell, How Cancer Begins Basic Books. Perseus Books Group, New York.

[79] Rosenberg, S.M. and Queitsch, C. (2014) Combating Evolution to Fight Disease. Science, 343, 1088-1089. https://doi.org/10.1126/science.1247472

[80] West, B.J. (2006) Where Medicine Went Wrong: Rediscovering the Path to Complexity (Studies of Nonlinear Phenomena in Life Science). World Scientific, New Jersey.

[81] Szigeti, G.P., Szasz, O. and Hegyi, G. (2017) Connections between Warburg's and Szentgyorgyi's Approach about the Causes of Cancer. Journal of Neoplasm, 1, 1-13.

[82] Gautherie, M. (1992) Hyperthermia and the Immune System. In: Gaucherie, M., Ed., Whole Body Hyperthermia: Biological and Clinical Aspects, Springer-Verlag, Berlin-Heidelberg-New York, 6-15. https://doi.org/10.1007/978-3-642-84596-3_2

[83] Lamon, E.W., Parrish, J., Marshall, G., et al. (1994) Synergistic Induction of Thermotolerance in Murine Natural Killer Cells by Interferon A and Mild Heat Shock. Radiation Research, 139, 364-369. https://doi.org/10.2307/3578836

[84] Dickson, J.A. and Shah, S.A. (1983) Immunologic Aspects of Hyperthermia. In: Storm, F.K., Ed., Hyperthermia in Cancer Therapy, G.K. Hall Publishers, Boston, 487-543.

[85] Dickson, J.A. and Shah, S.A. (1980) Hyperthermia and the Immune Response in Cancer Therapy. Cancer Immunology, Immunotherapy, 9, 1-10. https://doi.org/10.1007/BF00199521

[86] Shen, R.N., et al. (1994) Influence of Elevated Temperature on Natural Killer Cell Activity, Lymphokine-Activated Killer Cell Activity and Lectin-Dependent Cytotoxicity of Human Umbilical Cord Blood and Adult Blood Cells. International Journal of Radiation Oncology, Biology, Physics, 29, 821-826. https://doi.org/10.1016/0360-3016(94)90571-1

[87] Hietanen, T., Kapenen, M., Kellokumpu, L., et al. (2016) Restoring Natural Killer Cell Cytotoxicity after Hyperthermia Alone or Combined with Radiotherapy. Anti- 
cancer Research, 36, 555-564.

[88] Beachy, S.H. and Repasky, E.A. (2011) Toward Establishment of Temperature Thresholds for Immunological Impact of Heat Exposure in Humans. International Journal of Hyperthermia, 27, 344-352. https://doi.org/10.3109/02656736.2011.562873

[89] Skitzki, J.J., Repasky, E.A. and Evans, S.S. (2009) Hyperthermia as an Immunotherapy Strategy for Cancer. Current Opinion in Investigational Drugs, 10, 550-558.

[90] Falk, R.E., Moffat, F.L., Lawler, M., et al. (1986) Combination Therapy for Respectable and Unresectable Adenocarcinoma of the Pancreas. Cancer, 57, 685-688. https:/doi.org/10.1002/1097-0142(19860201)57:3<685:AID-CNCR2820570348>3.0.CO;2-X

[91] Keisari, Y. (2013) Tumour Ablation, Effects on Systemic and Local Anti-Tumour Immunity and on Other Tumour-Microenvironment Interactions. Springer, Dordrecht.

[92] Frey, B., Weiss, E.M., Rubner, Y., et al. (2012) Old and New Facts about Hyperthermia-Induced Modulations of the Immune System. Journal of Hyperthermia, 28, 1-15.

[93] Kobayashi, T., Kakimi, K., Nakayama, E. and Jimbow, K. (2014) Antitumour Immunity by Magnetic Nanoparticle-Mediated Hyperthermia. Nanomedicine, 9, 1715 1726. https://doi.org/10.2217/nnm.14.106

[94] Toraya-Brown, S. and Fiering, S. (2014) Local Tumour Hyperthermia as Immunotherapy for Metastatic Cancer. International Journal of Hyperthermia, 30, 531-539. https://doi.org/10.3109/02656736.2014.968640

[95] Manjili, M.H., Wang, X.Y., Park, J., et al. (2002) Cancer Immunotherapy: Stress Proteins and Hyperthermia. International Journal of Hyperthermia, 18, 506-520. https://doi.org/10.1080/02656730110116696

[96] Hasday, J.D. (1977) The Influence of Temperature on Host Defenses. In: Mackowiak, P.A., Eds., Fever: Basic Mechanisms and Management, Lippincott-Raven Publishers, Philadelphia, 177-196.

[97] Dickson, J.A. and Shah, S.A. (1982) Hyperthermia: The Immune Response and Tumour Metastasis. National Cancer Institute Monograph, 61, 183-192.

[98] Skeen, M.J., McLaren, J.R. and Olkowski, Z.L. (1986) Influences of Hyperthermia on Immunological Functions. In: Anghileri, L. and Robert, J., Eds., Hyperthermia in Cancer Treatment, CRC Press, Boca Raton, 93-105.

[99] Repasky, E. and Isseis, R. (2002) Physiological Consequences of Hyperthermia: Heat, Heat Shock Proteins and the Immune Response. International Journal of Hyperthermia, 18, 486-488. https://doi.org/10.1080/0265673021000036531

[100] Bull, J.M., Lees, D.E., Schuette, W.H., et al. (1982) Immunological and Physiological Responses to Whole-Body Hyperthermia. National Cancer Institute Monograph, 61, 177-181.

[101] Roberts, N.J., Lu, S.T. and Michaelson, S.M. (1985) Hyperthermia and Human Leucocyte Functions: DNA, RNA, and Total Protein Synthesis after Exposure to < $41^{\circ}$ or $>42.5^{\circ}$ Hyperthermia. Cancer Research, 45, 3076-3082.

[102] Knox, J.D., Mitchel, R.E. and Brown, D.L. (1991) Effects of Hyperthermia on Microtubule Organization and Cytolytic Activity of Murine Cytotoxic T Lymphocytes. Experimental Cell Research, 194, 275-283. https://doi.org/10.1016/0014-4827(91)90365-2

[103] Szasz, A. (2013) Electromagnetic Effects in Nanoscale Range. Cellular Response to Physical Stress and Therapeutic Applications. Nova Science Publishers, New York, Chapter 4 . 
[104] Szasz, A., Vincze, G.Y., Szasz, O. and Szasz, N. (2003) An Energy Analysis of Extracellular Hyperthermia. Magneto- and Electro-Biology, 22, 103-115. https://doi.org/10.1081/JBC-120024620

[105] Lee, S.Y. and Kim, M.G. (2015) The Effect of Modulated Electro-Hyperthermia on the Pharmacokinetic Properties of Nefopam in Healthy Volunteers: A Randomised, Single-Dose, Crossover Open-Label Study. International Journal of Hyperthermia, 31, 869-874. https://doi.org/10.3109/02656736.2015.1095358

[106] Hager, E.D., Dziambor, H., Höhmann, D., Gallenbeck, D., Stephan, M. and Popa, C. (1999) Deep Hyperthermia with Radiofrequencies in Patients with Liver Metastases from Colorectal Cancer. Anticancer Research, 19, 3403-3408.

[107] Szasz, A. (2014) Current Status of Oncothermia Therapy for Lung Cancer. The Korean Journal of Thoracic and Cardiovascular Surgery, 47, 77-93.

https://doi.org/10.5090/kjtcs.2014.47.2.77

[108] Andocs, G., Rehman, M.U., Zhao, Q.L., Tabuchi, Y., Kanamori, M. and Kondo, T. (2016) Comparison of Biological Effects of Modulated Electro-Hyperthermia and Conventional Heat Treatment in Human Lymphoma U937 Cell. Cell Death Discovery, 2, 16039. https://doi.org/10.1038/cddiscovery.2016.39

[109] Vincze, G.Y., Szigeti, G.Y., Andocs, G. and Szasz, A. (2015) Nanoheating without Artificial Nanoparticles. Biology and Medicine, 7, 249.

[110] Andocs, G., Rehman, M.U., Zhao, Q.L., Papp, E., Kondo, T. and Szasz, A. (2015) Nanoheating without Artificial Nanoparticles Part II. Experimental Support of the Nanoheating Concept of the Modulated Electro-Hyperthermia Method, Using U937 Cell Suspension Model. Biology and Medicine, 7, 1-9. https://doi.org/10.4172/0974-8369.1000247

[111] Vincze, G.Y. and Szasz, A. (2015) Reorganization of Actin Filaments and Microtubules by Outside Electric Field. International Journal of Advanced Biological and Biomedical Research, 8, 1514-1518.

[112] Szasz, A. (2015) Bioelectromagnetic Paradigm of Cancer Treatment Oncothermia. In: Rosch, P.J., Ed., Bioelectromagnetic and Subtle Energy Medicine, CRC Press, Boca Raton, 323-336.

[113] Andocs, G., Renner, H., Balogh, L., Fonyad, L., Jakab, C. and Szasz, A. (2009) Strong Synergy of Heat and Modulated Electro-Magnetic Field in Tumour Cell Killing, Study of HT29 Xenograft Tumours in a Nude Mice Model. Strahlentherapie und Onkologie, 185, 120-126. https://doi.org/10.1007/s00066-009-1903-1

[114] Jeon, T.W., Yang, H., Lee, C.G., Oh, S.T., et al. (2016) Electro-Hyperthermia Up-Regulates Tumour Suppressor Septin 4 to Induce Apoptotic Cell Death in Hepatocellular Carcinoma. International Journal of Hyperthermia, 7, 1-9.

[115] Cha, J., Jeon, T.W. and Lee, C.G. (2015) Electro-Hyperthermia Inhibits Glioma Tumourigenicity through the Induction of E2F1-Mediated Apoptosis. International Journal of Hyperthermia, 31, 784-792. https://doi.org/10.3109/02656736.2015.1069411

[116] Meggyeshazi, N., Andocs, G. and Krenacs, T. (2013) Programmed Cell Death Induced by Modulated Electro-Hyperthermia. Hindawi Publishing Corporation Conference Papers in Medicine, 2013, Article ID: 187835.

[117] Meggyeshazi, N., Andocs, G., Balogh, L., et al. (2014) DNA Fragmentation and Caspase-Independent Programmed Cell Death by Modulated Electrohyperthermia. Strahlentherapie und Onkologie, 190, 815-822.

https://doi.org/10.1007/s00066-014-0617-1

[118] Meggyeshazi, N. (2015) Studies on Modulated Electrohyperthermia Induced Tu- 
mour Cell Death in a Colorectal Carcinoma Model. Pathological Sciences Doctoral School, Semmelweis University, Budapest.

[119] Andocs, G. (2015) Preclinical Investigation on the Biological Effects of Modulated Electro-Hyperthermia. Graduate School of Medicine and Pharmaceutical Sciences, University of Toyama, Toyama.

[120] Andocs, G., Meggyeshazi, N., Balogh, L., et al. (2014) Upregulation of Heat Shock Proteins and the Promotion of Damage-Associated Molecular Pattern Signals in a Colorectal Cancer Model by Modualted Electrohyperthermia. Cell Stress Chaperones, 20, 37-46. https://doi.org/10.1007/s12192-014-0523-6

[121] Qin, W., Akutsu, Y., Andocs, G., et al. (2014) Modulated Electro-Hyperthermia Enhances Dendritic Cell Therapy through an Abscopal Effect in Mice. Oncology Reports, 32, 2373-2379. https://doi.org/10.3892/or.2014.3500

[122] Tsang, Y.W., Huang, C.C., Yang, K.L., et al. (2015) Improving Immunological Tumour Microenvironment Using Electro-Hyperthermia Followed by Dendritic Cell Immunotherapy. BMC Cancer, 15, 708. https://doi.org/10.1186/s12885-015-1690-2

[123] Szasz, O. and Szasz, A. (2016) Heating, Efficacy and Dose of Local Hyperthermia. Open Journal of Biophysics, 6, 10-18. https://doi.org/10.4236/ojbiphy.2016.61002

[124] Andocs, G., Szasz, O. and Szasz, A. (2009) Oncothermia Treatment of Cancer: From the Laboratory to Clinic. Electromagnetic Biology and Medicine, 28, 148-165. https://doi.org/10.1080/15368370902724633

[125] Szasz, A., Iluri, N. and Szasz, O. (2013) Local Hyperthermia in Oncology-To Choose or not to Choose? In: Huilgol, N., Ed., Hyperthermia, Intech, Rijeka, 1-82. https://doi.org/10.5772/52208

[126] Kleef, R., Kekic, S. and Ludwig, N. (2012) Successful Treatment of Advanced Ovarian Cancer with Thermochemotherapy and Adjuvant Immune Therapy. Case Reports in Oncology, 5, 212-215. https://doi.org/10.1159/000338617

[127] Lee, S.Y. and Lee, N.R. (2016) Positive Response of a Primary Leiomyosarcoma of the Breast Following Salvage Hyperthermia and Pazopanib. Korean Journal of Internal Medicine. (Epub. ahead of Print)

[128] Schrrmacher, V., Stücker, W., Lulei, M., et al. (2015) Long-Term Survival of a Breast Cancer Patient with Extensive Liver Metastases upon Immune and Virotherapy: A Case Report. Immunotherapy, 7, 855-860. https://doi.org/10.2217/imt.15.48

[129] Schrrmacher, V., Bihari, A.S., Stücker, W. and Sprenger, T. (2014) Long-Term Remission of Prostate Cancer with Extensive Bone Metastses upon Immuno- And Virotherapy: A Case Report. Oncology Letters, 8, 2403-2406.

[130] Lee, D.Y., Park, J.S., Jung, H.C., Byun, E.S., Haam, S.J. and Lee, S.S. (2015) The Outcome of the Chemotherapy and Oncothermia for Far Advanced Adenocarcinoma of the Lung: Case Reports of Four Patients. Advanced Lung Cancer, 4, 1-7. https://doi.org/10.4236/alc.2015.41001

[131] Yeo, S.G. (2015) Definitive Radiotherapy with Concurrent Oncothermia for Stage IIIB Non-Small-Cell Lung Cancer: A Case Report. Experimental and Therapeutic Medicine, 10, 769-772. https://doi.org/10.3892/etm.2015.2567

[132] Jeung, T.S., Ma, S.Y., Yu, J. and Lim, S. (2013) Cases that Respond to Oncothermia Monotherapy. Conference Papers in Medicine, 2013, Article ID: 392480. https://doi.org/10.1155/2013/392480

[133] Sahinbas, H., Groenemeyer, D.H.W., Boecher, E. and Szasz, A. (2007) Retrospective Clinical Study of Adjuvant Electro-Hyperthermia Treatment for Advanced BrainGliomas. Deutsche Zeitschrift für Onkologie, 39, 154-160. https://doi.org/10.1055/s-2007-986020 
[134] Fiorentini, G., Giovanis, P., Rossi, S., Dentico, P., Paola, R., Turrisi, G. and Bernardeschi, P. (2006) A Phase II Clinical Study on Relapsed Malignant Gliomas Treated with Electro-Hyperthermia. Vivo, 20, 721-724.

[135] Wismeth, C., Dudel, C., Pascher, C., Ramm, P., Pietsch, T., Hirschmann, B., Reinert, C., Proescholdt, M., Rümmele, P., Schuierer, G., Bogdahn, U. and Hau, P. (2010) Transcranial Electro-Hyperthermia Combined with Alkylating Chemotherapy in Patients with Relapsed High-Grade Gliomas-Phase I Clinical Results. Journal of Neuro-Oncology, 98, 395-405. https://doi.org/10.1007/s11060-009-0093-0

[136] Hager, E.D., Dziambor, H., App, E.M., Popa, C., Popa, O. and Hertlein, M. (2003) The Treatment of Patients with High-Grade Malignant Gliomas with RF-Hyperthermia. American Society of Clinical Oncology, 22, 2003.

[137] Lee, D.Y., Haam, S.J., Kim, T.H., Lim, J.Y., Kim, E.J. and Kim, N.Y. (2013) Oncothermia with Chemotherapy in the Patients with Small Cell Lung Cancer. Hindawi Publishing Corporation Conference Papers in Medicine, 2013, Article ID: 910363.

[138] Hager, E.D., Dziambor, H., Höhmann, D., Gallenbeck, D., Stephan, M. and Popa, C. (1999) Deep Hyperthermia with Radiofrequencies in Patients with Liver Metastases from Colorectal Cancer. Anticancer Research, 19, 3403-3408.

[139] Gadaleta-Caldarola, G., Infusino, S., Galise, I., et al. (2014) Sorafenib and Locoregional Deep Electro-Hyperthermia in Advanced Hepatocellular Carcinoma. A Phase II Study. Oncology Letters, 8, 1783-1787.

[140] Hager, E.D., Süsse, B., Popa, C., Schritttwieser, G., Heise, A. and Kleef, R. (1994) Complex Therapy of the Not in Sano Respectable Carcinoma of the Pancreas-A Pilot Study. Journal of Cancer Research and Clinical Oncology, 120, R47, P1.

[141] Volovat, C., Volovat, S.R., Scripcaru, V. and Miron, L. (2014) Second-Line Chemotherapy with Gemcitabine and Oxaliplatin in Combination with Loco-Regional Hyperthermia (EHY-2000) in Patients with Refrctory Metastatic Pancreatic Cancer-Preliminary Results of a Prospective Trial. Romanian Reports in Physics, 66, 166-174.

[142] Dani, A., Varkonyi, A., Magyar, T. and Szasz, A. (2008) Clinical Study for Advanced Pancreas Cancer Treated by Oncothermia. Forum Hyperthermie, 1, 13-20.

[143] Jeung, T.S., Ma, S.Y., Choi, J.H., Yu, J., Lee, S.Y. and Lim, S. (2015) Results of Oncothermia Combined with Operation, Chemotherapy and Radiation Therapy for Primary, Recurrent and Metastatic Sarcoma. Journal of Medical Case Reports, 4, 157-168.

[144] Volovat, C., Volovat, S.R., Scripcaru, V., Miron, L. and Lupascu, C. (2014) The Results of Combination of Ifosfamid and Locoregional Hyperthermia (EHY 2000) in Patients with Advanced Abdominal Soft-Tissue Sarcoma After Relapse of First Line Chemotherapy. Romanian Reports in Physics, 66, 175-181.

[145] Cremona, F., Pignata, A., Izzo, F., et al. (2003) Tolerability of External Electro-Hyperthermia in the Treatment of Solid Tumours. Tumouri, 89, 239-40.

[146] Lee, Y. (2013) Oncothermia Application for Various Malignant Diseases. Hindawi Publishing Corporation Conference Papers in Medicine, 2013, Article ID: 245156. https://doi.org/10.1155/2013/245156

[147] Baronzio, G., Parmar, G., Ballerini, M., Szasz, A., Baronzio, M. and Cassutti, V. (2014) A Brief Overview of Hyperthermia in Cancer Treatment. International Journal of Oncology, 3, 1. https://doi.org/10.4172/2329-6771.1000115

[148] Szasz, A., Baronzio, G., Jackson, M. and Lee, D.Y. (2013) Conference of the International Clinical Hyperthermia Society 2012. Hindawi Publishing Corporation Conference Papers in Medicine, 2013, Article ID: 690739. 
[149] Szasz, A. (2013) "Quo Vadis" Oncologic Hyperthermia? Hindawi Publishing Corporation Conference Papers in Medicine, 2013, Article ID: 201671.

[150] Szasz, A. and Morita, T. (2012) Heat Therapy in Oncology, New Paradigm in Hyperthermia. Nippon Hvoronsha, Tokyo.

[151] Lee, D.Y. and Szasz, A. (2016) Heat Therapy in Oncology, New Paradigm in Electro-Hyperthermia. Kim Jei Min Publishing, Seoul.

Submit or recommend next manuscript to SCIRP and we will provide best service for you:

Accepting pre-submission inquiries through Email, Facebook, LinkedIn, Twitter, etc. A wide selection of journals (inclusive of 9 subjects, more than 200 journals)

Providing 24-hour high-quality service

User-friendly online submission system

Fair and swift peer-review system

Efficient typesetting and proofreading procedure

Display of the result of downloads and visits, as well as the number of cited articles Maximum dissemination of your research work

Submit your manuscript at: http://papersubmission.scirp.org/

Or contact ojbiphy@scirp.org 